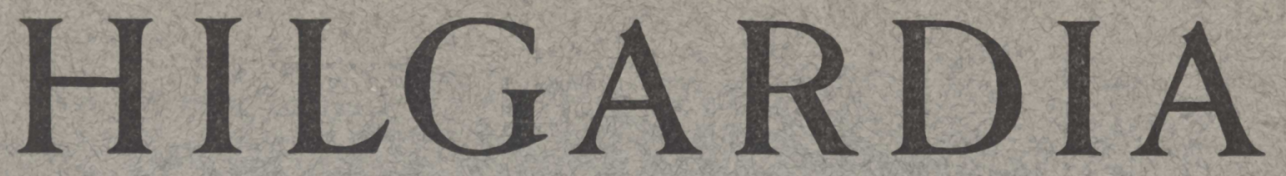

A Journal of Agricultural Science Publisbed by the California Agricultural Experiment Station

\title{
CONTENTS
}

\section{CHLORATE DISTRIBUTION AND THE EFFECT OF NITRATE CONCENTRATION ON CHLORATE TOXICITY IN SOIL COLUMNS}

R. S. ROSENFELS AND A. S. CRAFTS

\section{MOVEMENT OF \\ CARBON DISULFIDE VAPOR IN SOILS}

R. M. HAGAN

UNIVERSITY OF CALIFORNIA - BERKELEY, CALIFORNIA 


\section{MOVEMENT OF \\ CARBON DISULFIDE VAPOR IN SOILS}

R. M. HAGAN 



\title{
MOVEMENT OF \\ CARBON DISULFIDE VAPOR IN SOILS ${ }^{1,2}$
}

\author{
R. M. HAGAN ${ }^{3}$
}

\section{INTRODUCTION}

This investigation was undertaken to establish quantitatively the relation between each of several soil factors and the movement of carbon disulfide (bisulfide) through the soil. A method has been devised for measuring the movement of vapor through the soil under a constant total pressure and under carefully controlled soil conditions. Though designed for this particular problem, the general method and basis of attack on gaseous movement in soils may prove useful in general studies on soil aeration and soil structure.

This paper considers the mechanics of the method and the mathematical expression for gaseous flow ${ }^{4}$ in soils. It presents samples of data concerning the effect of soil factors on the measured flows of vapor. Complete data, with detailed discussion of the rôle of each soil factor, can more suitably be presented in a separate paper.

Success in using $\mathrm{CS}_{2}$ for weed and fungus control depends upon the movement of this vapor through the soil and upon the prevention of its escape from the soil surface during and immediately after treatment. For successful field application, therefore, one should know how each soil factor-porosity, texture, degree of compaction, moisture content, and temperature-affects $\mathrm{CS}_{2}$ vapor movement in and out of the soil. This laboratory program, the first part of which is herein reported, was planned to provide such knowledge.

With a proper background of basic facts derived from laboratory studies, the worker in the field should be able to plan more reliable experiments and perform them more efficiently, and thus arrive at generalized interpretations having wide-scale application. The ultimate purpose is to provide recommendations for commercial application of $\mathrm{CS}_{2}$ in weed control that will insure success at a minimum cost.

\footnotetext{
${ }^{1}$ Received for publication October 12, 1940.

2 This investigation was inaugurated and directed by the Division of Botany, College of Agriculture, under their weed control project. The work was supported by funds contributed to the Agricultural Experiment Station by the Wheeler, Reynolds, and Stauffer Chemical Company.

${ }^{3}$ Research Assistant in Soil Technology; resigned August 22, 1940.

"In this paper the words "flow" and "movement" are used interchangeably to express the transfer of vapor from one point to another, with no attempt to recognize the possible differences in their physical meanings.
} 


\section{FIELD USE OF CARBON DISULFIDE}

Carbon disulfide shows considerable promise as a herbicide for controlling deep-rooted perennials such as morning-glory (Convolvulus arvensis) and for treating oak root fungus (Armillaria mellea). That $\mathrm{CS}_{2}$ or its decomposition products $\left(\mathrm{SO}_{2}, \mathrm{SO}_{3}\right.$, and $\left.\mathrm{H}_{2} \mathrm{~S}\right)$ are highly toxic to plant life is widely known.

When $\mathrm{CS}_{2}$ is introduced below the surface as a liquid, it rapidly volatilizes and diffuses through the soil as a vapor. In treatment of morningglory, for example, the area is laid out into squares, a small hole made in the soil at the corners of the squares with a prod, a given dose of $\mathrm{CS}_{2}$ released at the bottom of each hole, and the hole closed by tamping. Large-scale applications are also made with an adapted subsoiler equipped with $\mathrm{CS}_{2}$ supply lines running down the back edges of the blade standards. Commercial treatments on morning-glory have, in general, been very promising; but satisfactory kills have not always been obtained. The failures are caused, apparently, by the inability of the $\mathrm{CS}_{2}$ to contact the roots with a toxic concentration for a sufficient time under the conditions of the treatment.

\section{HISTORICAL INTRODUCTION AND STATEMENT OF THE PROBLEM}

The movement of gases through soils has been little studied. Much of the published work has dealt with soil respiration and has presented generalized statements on soil aeration as related to plant growth. Of the work on the movement of gases through the soil, a large part has been carried out on systems of glass beads, sand, and the like, because of the complex interrelations involved in studying gaseous permeability of soils. Slichter (1897-98), ${ }^{5}$ who made a thorough contribution to the theoretical knowledge of pore space in artificial systems and in soils, derived an equation for liquid and gaseous flow involving Poiseuille's law. King (1897-98), testing Slichter's equations, found them applicable to several materials. Green and Ampt $(1911,1912)$, working with artificial systems and with soils, developed an expression of gaseous flow also based on Poiseuille's law. Furnas (1929) experimented extensively with systems involving high-pressure gradients. Buehrer (1932) used the movement of air through the soil to characterize soil structure. Muskat and Botset (1931). proved the validity of Darcy's law (1856) for gaseous flow in sands in response to a total-pressure gradient. Fancher, Lewis, and Barnes (1933), in a very extensive work, also expressed in terms of Darcy's law the

5ee "Literature Cited" at the end of this paper for complete data on citations, which are referred to in the text by author and date of publication. 
gaseous flows observed. Muskat and Botset, with their co-workers Wyckoff and Meres, have done much work on gaseous movement in relation to oil production since the publication of their paper in 1931.

Although all these workers have made valuable contributions, their deductions do not necessarily apply to soil aeration and soil fumigation, for they have been concerned with gaseous movement in response to a total-pressure gradient. In the particular problem for which the work reported here was done, however, and in soil-aeration studies as a whole, we are concerned with gaseous movement in response to a partial-pressure gradient rather than a total-pressure gradient. Only for a brief period after a change in the barometric pressure or a sudden cooling or heating of the soil surface does the total pressure have unequal values at various points in the soil. In normal soil the gaseous phase throughout is at a constant pressure. The movements of $\mathrm{CO}_{2}, \mathrm{O}_{2}$, and the other gases normally present, and the movement of the fumigants introduced, all result from differences in the concentrations or partial pressures of the particular gas from point to point.

Buckingham (1904) carried on experiments at constant pressure, measuring gaseous movement through a thin soil layer in response to a partial-pressure gradient of the gases. He stated his results in terms of a calculated diffusion coefficient, relating the observed flows to the porosity of the soil. Smith and Brown (1933) studied the diffusion of $\mathrm{CO}_{2}$ through soils and, using the well-known diffusion law, likewise expressed their results by use of the diffusion constant. Since, however, they were troubled with $\mathrm{CO}_{2}$ production by the soil during their period of measurement, their results are in doubt. More recently Higgins and Pollard (1937) have reported on the distribution of $\mathrm{CS}_{2}$ vapor through soils in large containers after the injection of the $\mathrm{CS}_{2}$ at a central point.

This paper deals in part with the development of suitable apparatus for studying gaseous movement in soils under a partial-pressure gradient with the total pressure constant. ${ }^{6}$ The use of the apparatus for evaluating the effect of each soil factor on the permeability of soil to gaseous movement under a partial-pressure gradient is indicated.

The measurement of gaseous flows at different temperatures has made it possible to show that the normal diffusion law is not followed in soils even under partial-pressure gradients. The data collected have allowed the formulation of an empirical equation, shown to hold accurately over

\footnotetext{
' Since this paper was prepared, there have appeared two articles by H. L. Penman of Rothamsted Experiment Station in which he describes an apparatus somewhat similar to the one devised for this investigation and draws a number of conclusions that are in substantial agreement with the results obtained by the present writer. (Penman, H. L. Gas and vapour movements in the soil. I. The diffusion of vapours through porous solids. II. The diffusion of carbon dioxide through porous solids. Jour. Agr. Sci. 30:437-62, 570-81. 1940.)
} 
the range of the experimental measurements. The relation of this empirical expression to the established laws of flow is discussed in a later section.

\section{GENERAL METHOD USED FOR GAS-FLOW MEASUREMENTS}

The handling of $\mathrm{CS}_{2}$ vapor and the measuring of its movement involves many experimental difficulties. Much time was consumed in developing suitable apparatus, which, however, when completed, proved adequate for measuring even small flows of $\mathrm{CS}_{2}$.

The apparatus (figs. 1 and 2) consists of a tube containing the soil to be analyzed, a shallow dish sealed to the lower end of the soil tube into which the liquid $\mathrm{CS}_{2}$ is measured, and an "air-sweeper" attached to the upper end of the soil tube. The $\mathrm{CS}_{2}$ is vaporized in the shallow dish; and the vapors, moving upward through the soil and rising from its upper surface, are collected by the air-sweeper and carried into absorber columns where the amount of $\mathrm{CS}_{2}$ may be chemically determined. The whole apparatus is housed in an insulated room provided with heating and cooling equipment so that the temperature may be controlled to $\pm 0.25^{\circ} \mathrm{C}$ and over a range of temperatures from about $5^{\circ}$ to $45^{\circ}$. The partialpressure gradient of the $\mathrm{CS}_{2}$ is controlled by carrying out the measurements at various temperatures.

Air-dry soils are packed into tubes with a compactor machine to a known compaction (apparent density value) and at a definite moisture content. Soils on which runs will be made at a moisture content near the field capacity are packed as air-dry soil with the compactor, irrigated, and allowed to stand until the moisture has distributed relatively uniformly. Soils to be run at intermediate moisture contents are packed by hand in small increments, each increment being wetted with the calculated amount of moisture by means of an atomizer.

The ability of the $\mathrm{CS}_{2}$ vapor to move through these soils is then determined by measuring the amount of $\mathrm{CS}_{2}$ collected in unit time by the absorber columns when the rate of flow has reached a "steady state," a condition to be described later.

The general method possesses several advantages for soil investigations. The flows measured take place in response to partial-pressure gradients of the sort that occur in normal soil. The system of sweeping the escaping gas into absorbers provides an easily obtained and continuous record of the outflow. The chemical determination of the gas and its expression on a mass basis eliminates correction of the flow for the pressure at time of measurement. The use in general soil-permeability and soil-structure studies of a gas like $\mathrm{CS}_{2}$, which does not occur in soils nor alters the soil structure, eliminates the complexities introduced by gases 
like $\mathrm{CO}_{2}$, which are affected by biological activity in the soil. The difficulties experienced by Smith and Brown (1933) in interpreting their results with $\mathrm{CO}_{2}$ have thus been avoided in the present studies.

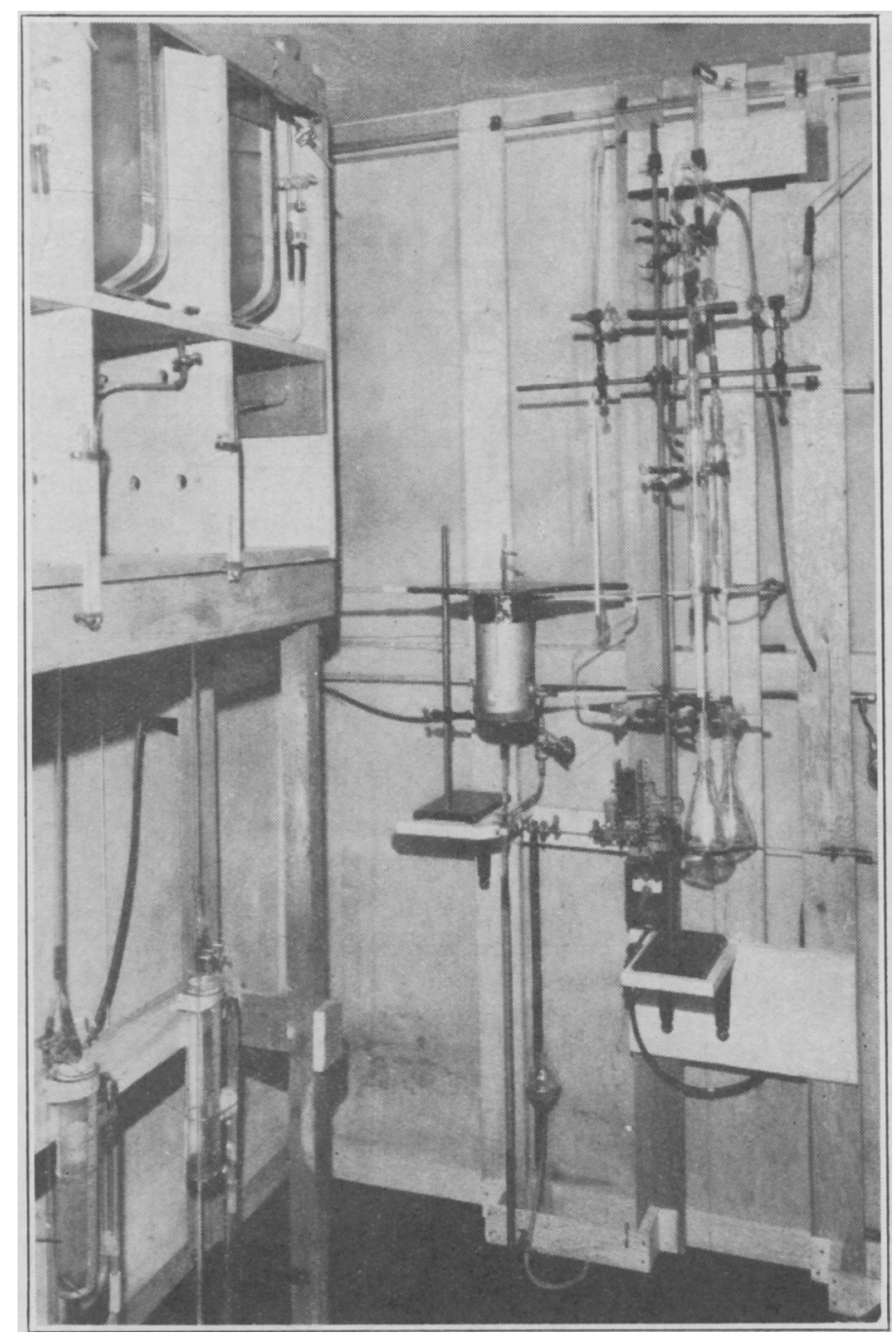

Fig. 1.-General view of the apparatus.

\section{DESCRIPTION OF APPARATUS AND MANNER OF OPERATION}

Apparatus required to measure $\mathrm{CS}_{2}$ vapor flow through soils under a given set of conditions is necessarily complicated. A detailed description follows, with an explanation of the operation of the various units. Tem- 
[VoL. 14, No. 2

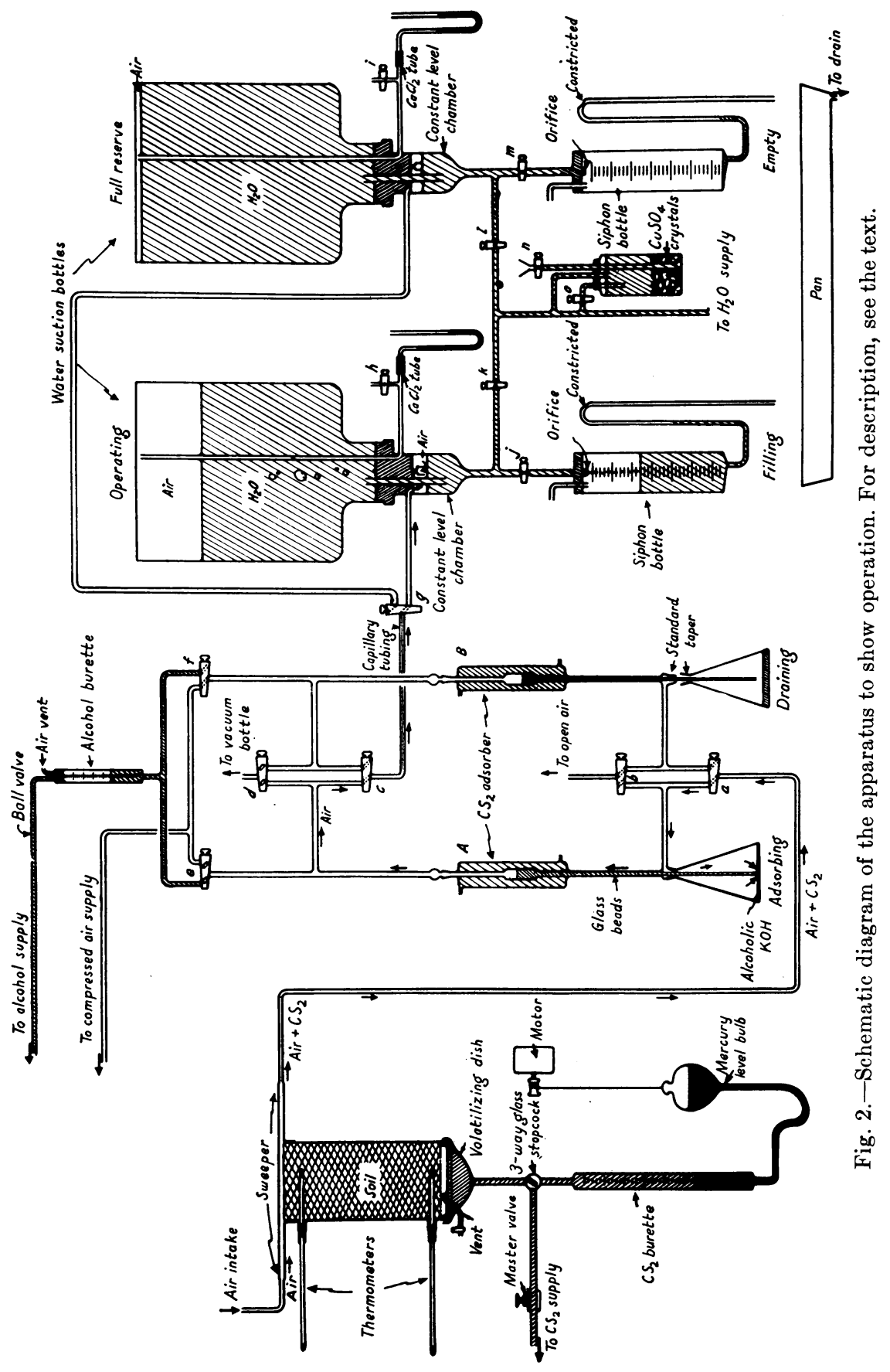


perature, an important factor in $\mathrm{CS}_{2}$ flow, requires careful regulation. The following description does not include temperature control, since all the equipment is housed in a constant-temperature room.

The relation of the various units comprising the apparatus is shown in the schematic diagram of figure 2. There are three parts: the soil tube with the volatilizing dish and sweeper, the absorption device with provision for washing out with alcohol, and the suction apparatus with means to record the volume of air drawn through the sweeper.

Volatilizing-Dish Unit.-Carbon disulfide is contained in a supply tank which, for safety, is mounted outside the building. Flow from the tank is controlled by the master valve.

To fill the volatilizing dish the three-way stopcock is opened and the mercury leveling bulb lowered, drawing liquid $\mathrm{CS}_{2}$ into the burette. This stopcock is closed to the supply line and opened to the volatilizing dish, into which the $\mathrm{CS}_{2}$ is loaded slowly by raising the mercury bulb.

The liquid $\mathrm{CS}_{2}$, vaporizing, moves up through the soil into the sweeper, where an air stream carries it to the absorbers.

Absorber Unit.-Air plus $\mathrm{CS}_{2}$ moves down into absorber flasks containing saturated alcoholic $\mathrm{KOH}$. (See section on the chemistry involved in the analysis.)

Suction, applied at the top of the absorber columns, first draws the alcoholic $\mathrm{KOH}$ up into the glass beads. When the tip of the stem is freed, air plus $\mathrm{CS}_{2}$ begins to bubble up. The $\mathrm{CS}_{2}$ reacts with and is removed by the alcoholic $\mathrm{KOH}$, while the air continues out the top.

The two absorber columns, $A$ and $B$, form a parallel system. By operating stopcock $a$ and stopcock $c$, which control the suction, one can cause the $\mathrm{CS}_{2}$-laden air from the sweeper to flow into either absorber $A$ or $B$. In the diagram of figure 2 absorber $A$ is receiving the air, while $B$ is being drained and washed down with alcohol. This double absorption unit allows the air from the sweeper to be continuously analyzed.

The alcohol burette and stopcocks $e$ and $f$ allow for alternate washing down with alcohol and blowing out with compressed air.

The alcoholic $\mathrm{KOH}$ plus the $\mathrm{CS}_{2}$ absorbed and the alcohol washings collect in the flask, which is then removed, stoppered, and later titrated.

Water-Suction Unit.-To produce the suction causing air flow through the sweeper, a special adaptation has been made of the Mariotte flask as used by Moore (1939). Water flows out of the suction bottles, causing air to be drawn into the container and to collect over the water.

The rate at which water may flow through an orifice depends on the size of that orifice and the head of water above it. If one were simply to draw air into a bottle as the water ran out, the rate at which air would be taken would decrease as the bottle emptied. To provide for a steady flow 
of air, the Mariotte principle is used to give a constant head of water over the orifice in the siphon bottle regardless of the level in the suction bottle. When the water level drops in the "constant level chamber," the lower end of the flared tube is freed, the water meniscus breaks, and air is ad-

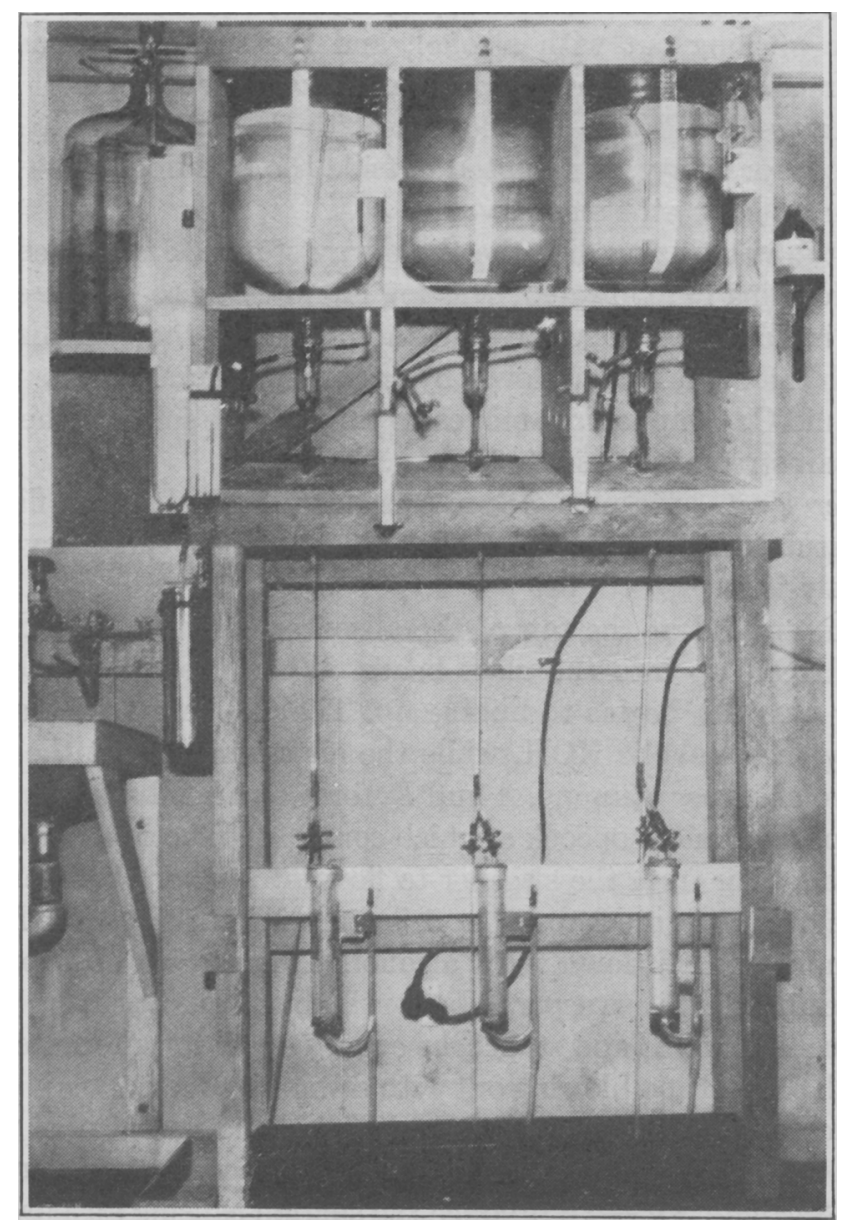

Fig. 3.-Water-suction unit. For description, see the text.

mitted to the bottle, raising the water level in the chamber until the end of the flared tube is again immersed and the air supply cut off. This cycle continuously repeated would cause periodic surges of air through the system. Because the air stream must be steady, not periodic, a section of 1-mm glass capillary tubing is interposed. The resistance to flow through 
this tube is adjusted so as to minimize the effect of the pulsations resulting in a steady suction at the top of the absorber columns.

It is also necessary to know the volume of air drawn over the soil in the sweeper during a given period. This is determined by measuring the rate of water outflow from the suction bottles. Because of the inaccuracy in reading small volume changes in a large supply bottle, the water flows from the orifice into a siphon bottle, which automatically empties as it becomes filled. The number of times the siphon bottle has emptied is recorded on a scale on the suction bottle.

Figure 3 shows the water-suction apparatus. In the upper part of the rack are the suction bottles, to which are attached the "constant-level chambers." At the bottom are the siphon bottles. The manometers below and to the left of each suction bottle register the negative pressure over the water. When a suction bottle becomes empty, the suction line from the apparatus is transferred to an adjacent bottle by operation of stopcocks, so that a continuous air stream may be maintained over long periods.

Figure 1 indicates the actual arrangement of the apparatus, with the water-suction bottles on the left, the soil tube with $\mathrm{CS}_{2}$ burette and loading bulb in the center, and absorber columns on the right. Figure 4 shows the volatilizing dish, the soil tube, and the sweeper in greater detail.

The volatilizing dish is made of copper to provide for maximum heat conduction from the outside air to replace that required to vaporize the $\mathrm{CS}_{2}$. The bottom is dome-shaped, with the supply tube at the low point to allow the liquid $\mathrm{CS}_{2}$ to be drained away at the end of a run and thus to make possible a check on the quantity of $\mathrm{CS}_{2}$ that has moved up into and through the soil column. A capillary vent keeps the pressure in the volatilizing dish equal to atmospheric pressure.

The soil tube rests in a $U$-shaped trough with liquid mercury as a seal. The soil is retained by an 80 -mesh screen fastened into a detachable collar that fits the bottom of the soil tube. Figure 4 shows two thermometers fitted into the side of the tube and held by metal support sleeves inclined at a small angle above horizontal. Only a few tubes were equipped thus, for it was found that temperature fluctuations of $\pm 0.25^{\circ} \mathrm{C}$ in the control room caused no perceptible variation of the thermometers in the soil.

Careful checks were made on the following possible sources of difficulty. The basic assumption made in the measurements requires that an atmosphere saturated with $\mathrm{CS}_{2}$ be maintained under the soil column at all times during runs and at all temperatures. That this assumption is valid is indicated by tests showing that the rate of flow through the soil column was not affected by a change in shape of the volatilizing dish or by removal of all but a few cubic centimeters of the liquid $\mathrm{CS}_{2}$. Further, it had 
to be possible to load the volatilizing dish with the highly volatile $\mathrm{CS}_{2}$ without increasing the total pressure on the lower face of the soil column. By introducing the $\mathrm{CS}_{2}$ slowly, it was possible to meet this requirement, as indicated by the lack of a detectable reading in the arms of a carefully
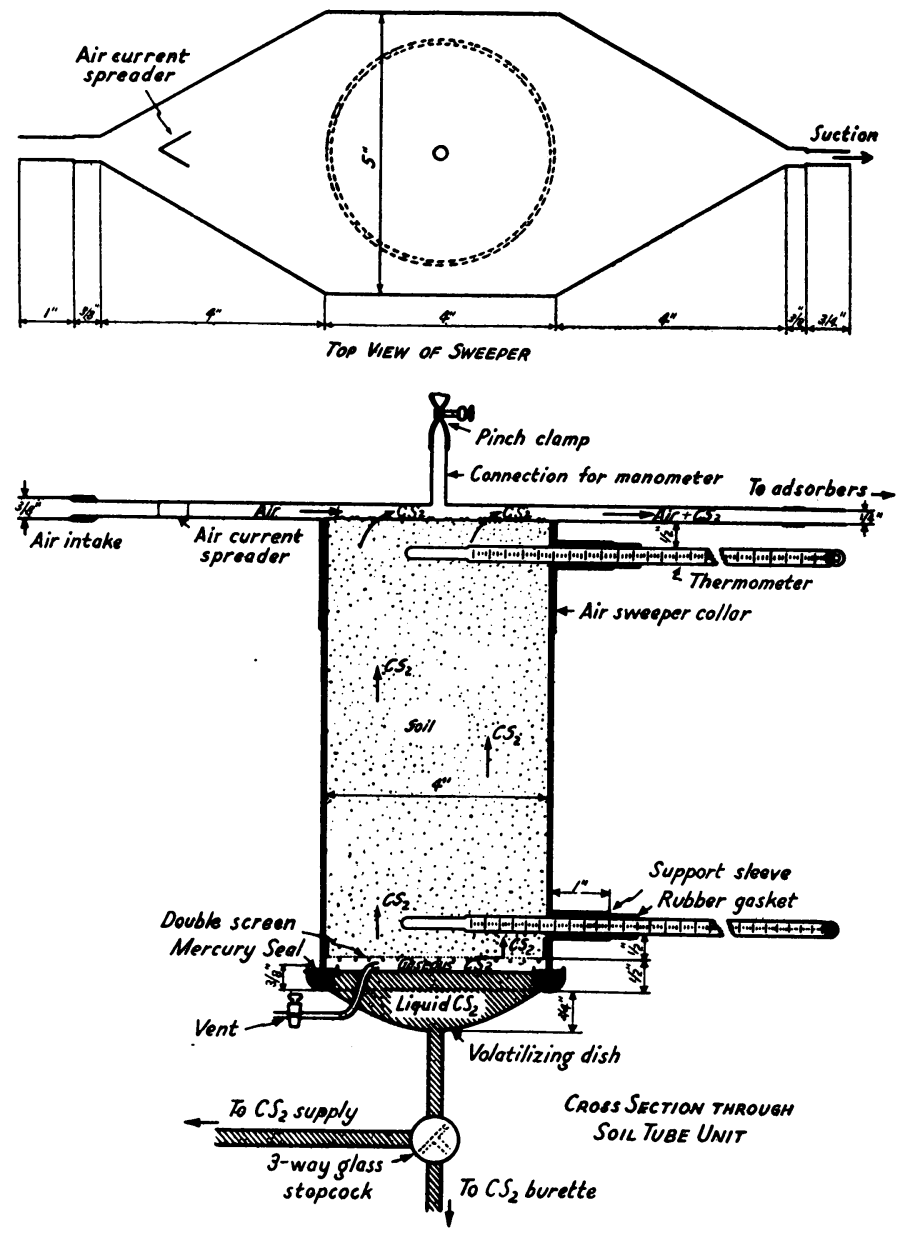

Fig. 4.-Soil tube, volatilizing dish, and sweeper. For description, see the text.

prepared water manometer during the loading of the $\mathrm{CS}_{2}$. The rate of air flow over the soil had to be accurately controlled and measured, for it affected the rate of flow of $\mathrm{CS}_{2}$ from the soil by changing the partial pressure of $\mathrm{CS}_{2}$ in the sweeper. The air-flow rate remained surprisingly con- 
stant through a wide range of temperatures. In one case the extreme values for the air-flow rate were 60.8 to $61.7 \mathrm{cc}$ per minute over a temperature range of $10^{\circ}$ to $45^{\circ} \mathrm{C}$.

\section{ANALYSIS FOR CARBON DISULFIDE}

The flasks attached to the absorber columns contain a saturated solution of $\mathrm{KOH}$ in 95 per cent ethyl alcohol (approximately $30 \mathrm{gm} \mathrm{KOH}$ per 100 cc alcohol). The $\mathrm{CS}_{2}$ is removed from the air stream as it bubbles up through the columns by the following reaction, resulting in the formation of a soluble xanthate:

$$
\mathrm{CS}_{2}+\mathrm{KOH}+\mathrm{C}_{2} \mathrm{H}_{5} \mathrm{OH}=\underset{\text { (xanthate) }}{\mathrm{C}_{2} \mathrm{H}_{5} \mathrm{OCS}_{2} \mathrm{~K}}+\mathrm{H}_{2} \mathrm{O}
$$

The $\mathrm{C}_{2} \mathrm{H}_{5} \mathrm{OH}$ and $\mathrm{KOH}$ do not react until the $\mathrm{CS}_{2}$ is introduced. To make this reaction go to completion, no water should be present, and none should be added until titration in order to avoid possible decomposition of the xanthate on standing, through a reversal of the reaction.

From this point on, the procedure involves routine chemical analysis following the techniques described by Fleming and Baker (1935) and Matuszak (1932). The sample is diluted with $\mathrm{H}_{2} \mathrm{O}$, neutralized to the phenolphthalein end point with glacial acetic acid, and then titrated with standard $\mathrm{I}_{2}$ solution, using a starch indicator. The reactions are these:

$$
\begin{aligned}
& \text { neutralization, } \\
& \qquad \mathrm{C}_{2} \mathrm{H}_{5} \mathrm{OCS}_{2} \mathrm{~K}+\mathrm{CH}_{3} \mathrm{COOH}=\underset{\text { (xanthic acid) }}{\mathrm{C}_{2} \mathrm{H}_{5} \mathrm{OCS}_{2} \mathrm{H}}+\mathrm{CH}_{3} \mathrm{COOK}
\end{aligned}
$$$$
\text { I titration, } 2 \mathrm{C}_{2} \mathrm{H}_{5} \mathrm{OCS}_{2} \mathrm{H}+\mathrm{I}_{2}=2 \mathrm{C}_{2} \mathrm{H}_{5} \mathrm{OCS}_{2}+2 \mathrm{HI}
$$

(dixanthogen)

During the titration the dixanthogen forms a milky emulsion that conveniently serves as a white background for easy detection of the bluecolored starch end point.

\section{DEFINITION OF STEADY-STATE CONDITION}

All values for the flow of $\mathrm{CS}_{2}$ vapor and the soil permeability are based on "steady-state conditions," as is customary in such studies. For a period immediately following the introduction of $\mathrm{CS}_{2}$ into the volatilizing dish, the rate at which $\mathrm{CS}_{2}$ left the soil surface increased with time and gradually approached a steady value. At the same time as the $\mathrm{CS}_{2}$ was introduced into the volatilizing dish, the air-sweeping and collection of samples was started. Thereafter, samples were taken at one-half hour intervals. The data for a typical run appear in table 1. 
Curves plotted from such data form the basis of our definition of "steady-state" flow. Flow is considered to have attained steady state when the measured flow rate remains relatively constant with time.

The time required for reaching steady state depends on the length of the soil column. Although complete flow curves from zero time to steady state were not made in the later comparative studies, texture, and espe-

TABLE 1

Rate of $\mathrm{CS}_{2}$ Vapor Flow as a Function of Elapsed Time Following Introduction OF $\mathrm{CS}_{2}$ INTO The Volatilizing Dish*

\begin{tabular}{|c|c|c|c|}
\hline Time interval & $\begin{array}{l}\text { Fine sand; } \\
\text { length of } \\
\text { soil column, } \\
10.65 \mathrm{~cm}\end{array}$ & $\begin{array}{l}\text { Fine sand; } \\
\text { length of } \\
\text { soil column, } \\
19.95 \mathrm{~cm}\end{array}$ & $\begin{array}{l}\text { Clay loam; } \\
\text { length of } \\
\text { soil column, } \\
21.20 \mathrm{~cm}\end{array}$ \\
\hline hours & $m g / \min . \dagger$ & $\operatorname{mg} / \min . \dagger$ & $m g / \min . \dagger$ \\
\hline $0-1 / 2 \ldots \ldots \ldots \ldots \ldots \ldots \ldots \ldots \ldots \ldots \ldots$ & 2.28 & 0.86 & 0.03 \\
\hline $1 / 2-1 \quad \ldots \ldots \ldots \ldots \ldots \ldots \ldots \ldots \ldots \ldots$ & 7.75 & 1.31 & 0.04 \\
\hline $1-11 / 2 \ldots \ldots \ldots \ldots \ldots \ldots \ldots \ldots \ldots \ldots$ & - & - & 3.19 \\
\hline $11 / 2-2 \quad \ldots \ldots \ldots \ldots \ldots \ldots \ldots \ldots \ldots \ldots \ldots \ldots \ldots$ & - & - & - \\
\hline $2 \quad-21 / 2 \ldots \ldots \ldots \ldots \ldots \ldots \ldots \ldots \ldots \ldots \ldots$ & 8.30 & 2.74 & - \\
\hline $21 / 2-3 \quad \ldots \ldots \ldots \ldots$ & 8.95 & 3.71 & - \\
\hline $3-31 / 2 \ldots \ldots \ldots \ldots$ & 9.14 & 3.76 & 4.72 \\
\hline $31 / 2^{-4} \quad \ldots \ldots \ldots \ldots \ldots \ldots \ldots \ldots \ldots \ldots \ldots \ldots \ldots$ & - & - & 5.06 \\
\hline $4-41 / 2 \ldots \ldots \ldots \ldots \ldots \ldots \ldots \ldots \ldots \ldots \ldots \ldots$ & 9.27 & 3.67 & - \\
\hline $41 / 2-5 \quad \ldots \ldots \ldots \ldots \ldots \ldots \ldots \ldots \ldots \ldots \ldots \ldots$ & 8.72 & 4.25 & 5.26 \\
\hline $5 \quad-51 / 2 \ldots \ldots \ldots$ & 9.21 & 4.00 & 5.35 \\
\hline $51 / 2-6 \quad \ldots \ldots$ & - & - & 5.47 \\
\hline $6-61 / 2 \ldots \ldots$ & 9.05 & 4.12 & 5.43 \\
\hline $61 / 2-7 \quad \ldots \ldots$ & 9.31 & 4.06 & 5.36 \\
\hline $7-71 / 2 \ldots \ldots \ldots \ldots \ldots \ldots \ldots \ldots \ldots \ldots \ldots$ & 9.05 & 4.09 & 5.45 \\
\hline $71 / 2-8 \quad \ldots \ldots \ldots \ldots \ldots \ldots \ldots \ldots \ldots \ldots \ldots$ & 9.16 & 4.12 & 5.46 \\
\hline $8-81 / 2 \ldots \ldots \ldots \ldots \ldots \ldots \ldots \ldots \ldots \ldots \ldots \ldots$ & 9.16 & 4,11 & 5.35 \\
\hline $81 / 2-9 \quad \ldots \ldots \ldots \ldots \ldots \ldots \ldots \ldots \ldots \ldots \ldots \ldots$ & $\ldots$ & $\ldots$ & 5.54 \\
\hline
\end{tabular}

* The rates of $\mathrm{CS}_{2}$ vapor flow entered in the table as $\mathrm{mg} / \mathrm{min}$. refer to the mean rate of movement of the $\mathrm{CS}_{2}$ vapor through the soil during the time interval shown.

t Dashes indicate cases where readings were not taken in the half-hour interval; the first value set below the dash gives the mean rate calculated for the longer time interval.

cially moisture content, seemed to influence the time required for reaching steady state. In every case, soils with a high moisture content attained steady state before the drier soils.

\section{PHYSICAL BASIS OF MEASUREMENTS AND DEVELOPMENT OF FLOW EQUATION}

To express quantitatively the results of studies on flow of gases and vapors through soils, a mathematical formulation of the relations of the several measurable factors is needed. The ability of a uniform porous medium to conduct a fluid flowing with viscous motion is generally called its permeability. What is wanted, then, is an expression for the permeability of the soil under a given set of conditions, together with a mathe- 
matical relation that will permit evaluation of the change in permeability produced by variation of one given factor.

As has been pointed out in a previous section, we are here concerned with gaseous flow in response to a partial-pressure gradient, the total pressure throughout the system being constant. Flow under these conditions is commonly called diffusion. Diffusion studies have been made largely in a system where the two components, at first held apart, are subsequently allowed to mix in the absence of any barrier between them. This free diffusion finds mathematical expression in the well-established kinetic-theory equation:

$$
\frac{N}{A t}=D_{f} \frac{(d P)}{(d L)}
$$

where $N$ is the number of molecules diffusing, expressible in mass or volume units, through a cross-sectional area $A$ in time $t, d P / d L$ is the rate of change of the partial pressure of the constituent in the direction of diffusional flow, and $D_{f}$ is the diffusion coefficient. In soils, however, we are dealing not with free diffusion, but with diffusion through a porous material.

Now the question arises whether the law of diffusion as given by equation 1 can apply to the movement of gases through soil under a partialpressure gradient. Gaseous flow in soils under these conditions has been measured by Buckingham (1904) and by Smith and Brown (1933). The former has expressed his measured flows in terms of a calculated diffusion constant $D_{s}$, which he found could be related to the square of the soil porosity ${ }^{7} S$ and to the free diffusion coefficient $D_{f}$ for the gases used in the following manner:

$$
D_{s}=S^{2} D_{f}
$$

Several workers, including Smith and Brown, have doubted the correctness of evaluating the rôle of the soil by means of the square of the porosity. However, it seems safe to state in general terms that the calculated diffusion constant $D_{s}$ is related as follows:

$$
D_{s}=f\left(\text { soil) } D_{f}=C D_{f}\right.
$$

where $f$ (soil) merely indicates some function of the soil that may be written as a constant $C$ for a given soil under a particular set of conditions.Then to make the law of diffusion, as given in equation 1, applicable to the flow of gases through soils, the diffusion coefficient $D_{f}$ must be replaced by $C D_{f}$. The expression then becomes

$$
\frac{N}{A t}=C D_{f} \frac{(d P)}{(d L)}
$$

\footnotetext{
${ }^{7}$ See page 108 for definition of porosity.
} 
If the flow is expressed in mass units and the differential expression for rate of change of partial pressure with distance along the direction of flow is replaced by the average value of the gradient $\frac{\left(P_{b}-P_{t}\right)}{L}$, where subscripts $b$ and $t$ are introduced for convenience in later comparisons with data obtained in the present work and refer to partial pressures of $\mathrm{CS}_{2}$ at the bottom and top of soil column respectively, equation 4 becomes

$$
\frac{Q_{m}}{A t}=C D_{f} \frac{\left(P_{b}-P_{t}\right)}{L}
$$

Here $Q_{m}$ is the mass of gas in grams flowing through soil column, $A$ is the cross-sectional area of soil column in square centimeters, and $t$ is the time in seconds during which the quantity $Q_{m}$ was collected. Though neither Buckingham nor Smith and Brown have carried the analysis to the point of writing the formal expression of a diffusional equation 5 , such an equation must follow from their statements.

To test the validity of applying the law of diffusion, as written in 5, to the flow of gases under a partial-pressure gradient through soils, two sets of experiments were performed. A discussion follows.

Partial-Pressure Difference and Temperature Constant; Length of Soil Column Varied.-Using a given soil, successive samples of which were packed into tubes under as nearly uniform conditions as possible, the partial-pressure difference $\left(P_{b}-P_{t}\right)$ and the temperature $T$ were held constant while the effect of varying the tube length $L$ was studied. Such tests were carried out on soils of five different textures. Table 2 contains the data for flow of $\mathrm{CS}_{2}$ vapor measured as $Q_{m} / A t$ for different lengths of soil column.

The data suggest that the product $Q_{m} / A t$ by $L$ is equal to a constant for each soil in a given condition as regards moisture content, compaction, and the like. The weighted mean ${ }^{8}$ value $M$ of this product for each soil appears in the table. To provide a measure of the exactness with which the product $\left(Q_{m} / A t\right) \times(L)$ is a constant for each soil, an estimate of the probable error of a single observation has been calculated by the method of Deming and Birge (1934), which permits an "optimum" estimate of the probable error to be made by combining observations on the five different soils. Since the method of Deming and Birge assumes that observations made on each of the five soils have the same precision, a condition not strictly true in the present case, the calculated "optimum" probable error is an approximation with a value of \pm 0.695 . On the average, accordingly, there is an even chance that the product $\left(Q_{m} / A t\right) \times(L)$ will fall within \pm 0.695 of the true mean for each soil.

\footnotetext{
${ }^{8}$ Weighted as to number of observations.
} 
It is a necessary, but not a sufficient, condition that the product $\left(Q_{m} / A t\right) \times(L)$ be a constant if the law of diffusion as given in equation 5 is to be followed. We cannot infer from this experiment that the law is obeyed. A second set of experiments is required to interpret more correctly the application of this diffusion law.

TABLE 2

$\mathrm{CS}_{2}$ Vapor Flow as a Function of Length of Soll Column with Partial-Pressure Difference and the Temperature Constant

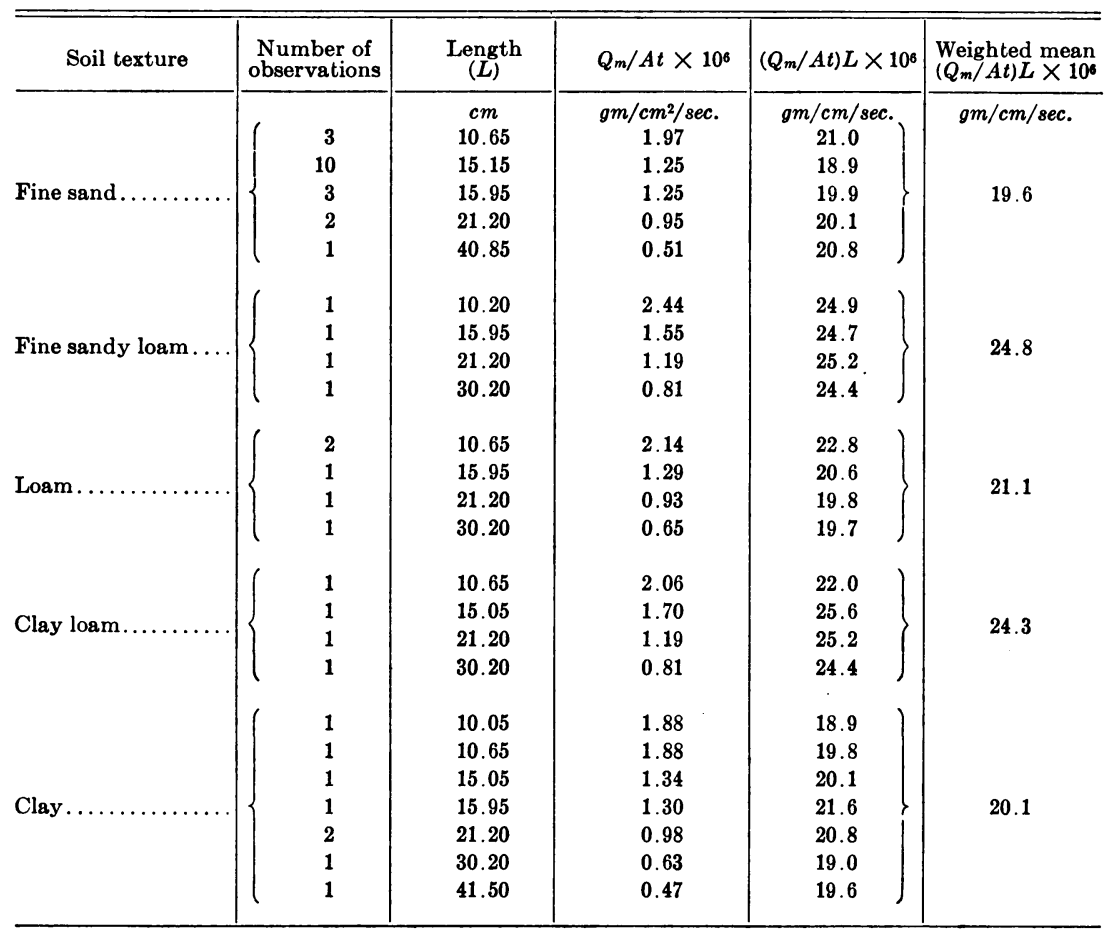

Length of Soil Column Constant; Partial-Pressure Difference Varied by Altering Temperature.-The tube length $L$ was now held constant, and the partial-pressure difference $\left(P_{b}-P_{t}\right)$ varied by changing the temperature of the apparatus. $P_{b}$, the partial pressure of the $\mathrm{CS}_{2}$ in the volatilizing dish, directly depends on temperature. In table 3 the measured flows of $\mathrm{CS}_{2}, Q_{m} / A t$, are given in column 2; the corresponding gradients, $\frac{\left(P_{b}-P_{t}\right)}{L}$, in column 6 .

This series of experiments permits more critical examination of the question whether the diffusion law of equation 5 is obeyed for the move- 


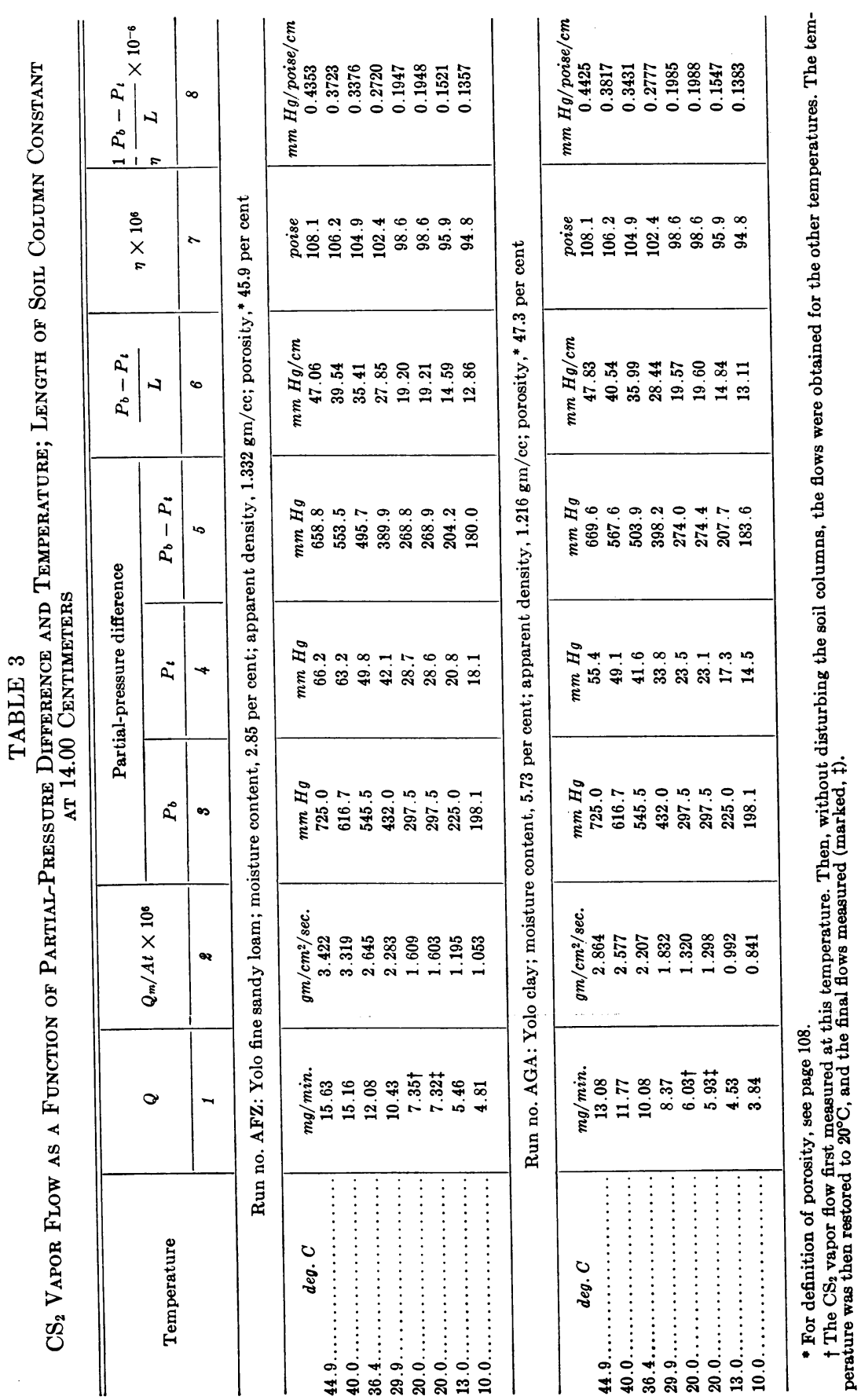


ment of $\mathrm{CS}_{2}$ vapor through soil in response to a partial-pressure gradient. Under the experimental conditions, as the gradient $\frac{\left(P_{b}-P_{t}\right)}{L}$ increases, the temperature $T$ must also increase. The possible effect of temperature on the $C D_{f}$ term of equation 5 must be considered. $C$ is presumably a constant dependent only on the soil and independent of temperature. According to kinetic theory, however, the free diffusion coefficient $D_{f}$ depends on temperature. Its relation to temperature, according to Kennard (1938), may be approximated by

$$
D_{f} \propto T^{1.75 \text { to } 2}
$$

where for $\mathrm{CS}_{2}$ the exponent is set equal to 2. (As given in International Critical Tables, vol. 5, p. 62. National Research Council. 1929.)

Now if the diffusion law postulated in equation 5 is to be followed, assuming $C$ to be independent of temperature, then the mass flow of $\mathrm{CS}_{2}$ per unit area per unit time, $Q_{m} / A t$, plotted against the partial-pressure gradient $\frac{\left(P_{b}-P_{t}\right)}{L}$ should give a curve having at all points a slope equal to $C D_{f}$. Since $T$ increases with $\frac{\left(P_{b}-P_{t}\right)}{L}$ and $D_{f}$ increases as $T^{2}$, the slope $C D_{f}$ must increase with increasing values of $\frac{\left(P_{b}-P_{t}\right)}{L}$. Hence $Q_{m} / A t$ plotted as ordinates against $\frac{\left(P_{b}-P_{t}\right)}{L}$ as abscissas should not yield a straight line, but rather an upward-bending curve of increasing slope (figs. 5 and 6).

In these graphs the experimentally observed flow curve is compared with one drawn through a series of points calculated by assuming the diffusion law as given in equation 5 . These values of flow, designated by $\left(Q_{m} / A t\right)_{d}$, have been calculated in the following way:

Since duplicate determinations were available at $20^{\circ} \mathrm{C}$, the experimentally obtained values of $Q_{m} / A t$ and $\frac{\left(P_{b}-P_{t}\right)}{L}$ at this temperature, together with the known value of the diffusion coefficient $D_{f}$ at $20^{\circ} \mathrm{C}$, have been used to give a mean value of the constant $C$ of equation 5 for each soil. This has been assumed to be a reliable estimate of $C$. Now if $C$ is a constant independent of temperature, it may be used with values of $D_{f}$ to calculate $\left(Q_{m} / A t\right)_{d}$ for each experimental value of $\frac{\left(P_{b}-P_{t}\right)}{L}$. (The subscript $d$ is introduced to denote calculated values according to diffusion law.) Table 4 summarizes these calculations. 


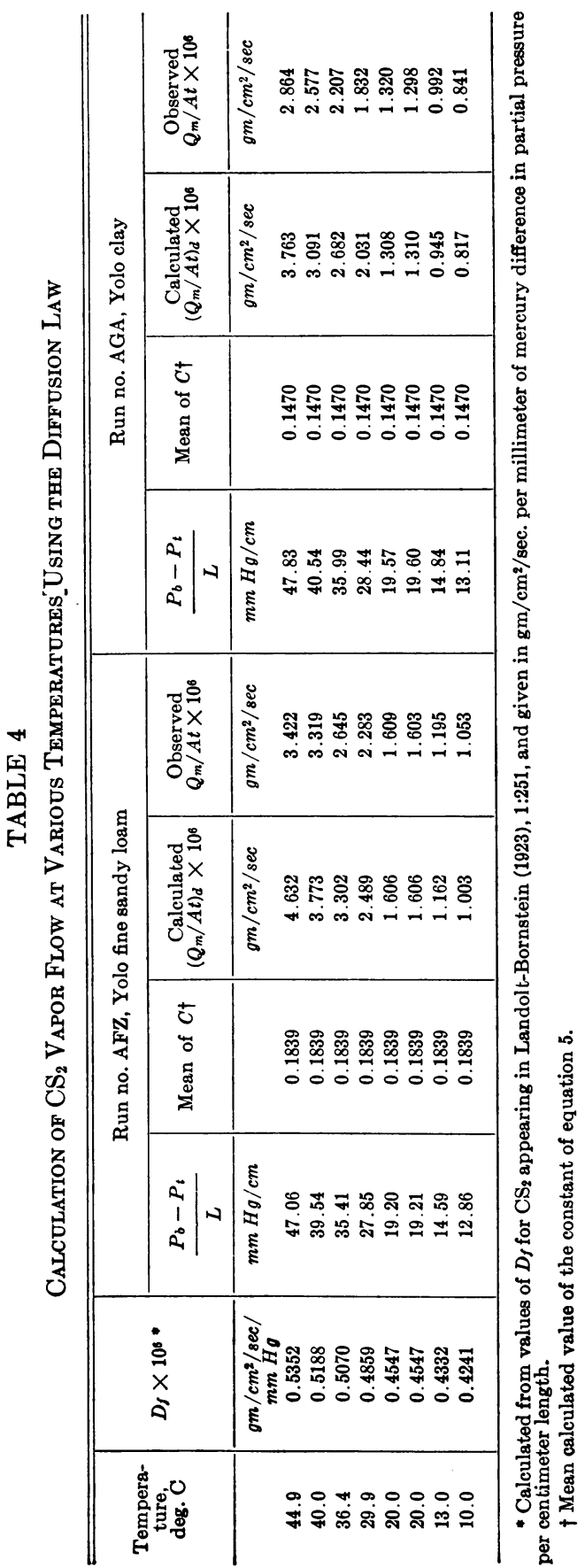




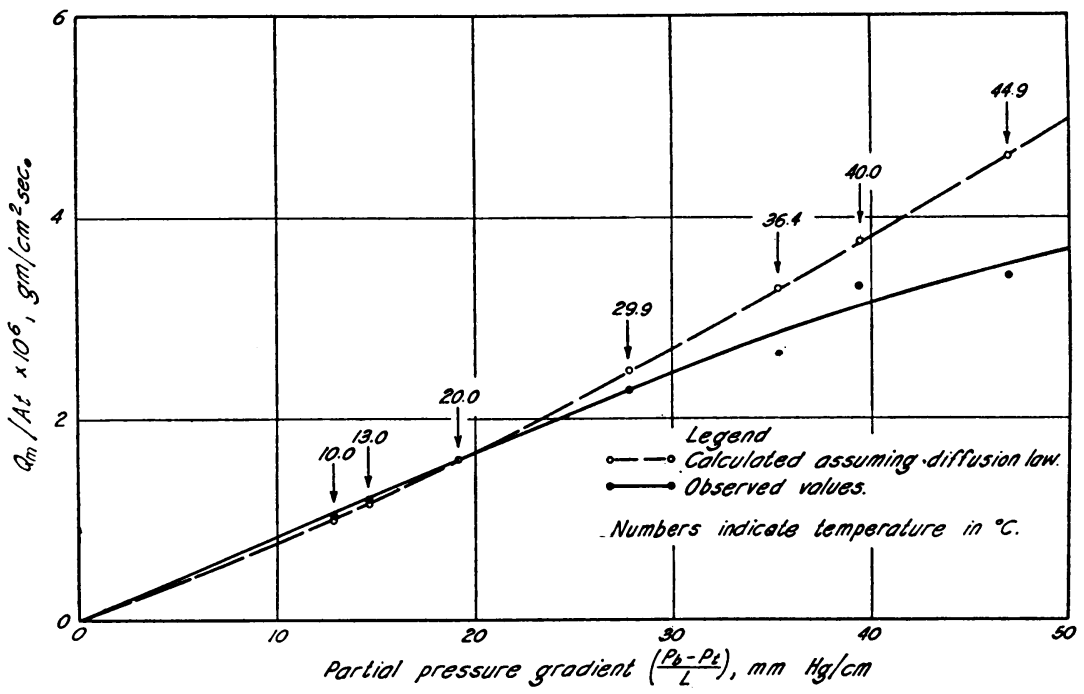

Fig. 5.-Departure of observed flow of $\mathrm{CS}_{2}$ vapor from flow values calculated by assuming diffusion law for run no. AFZ (Yolo fine sandy loam).

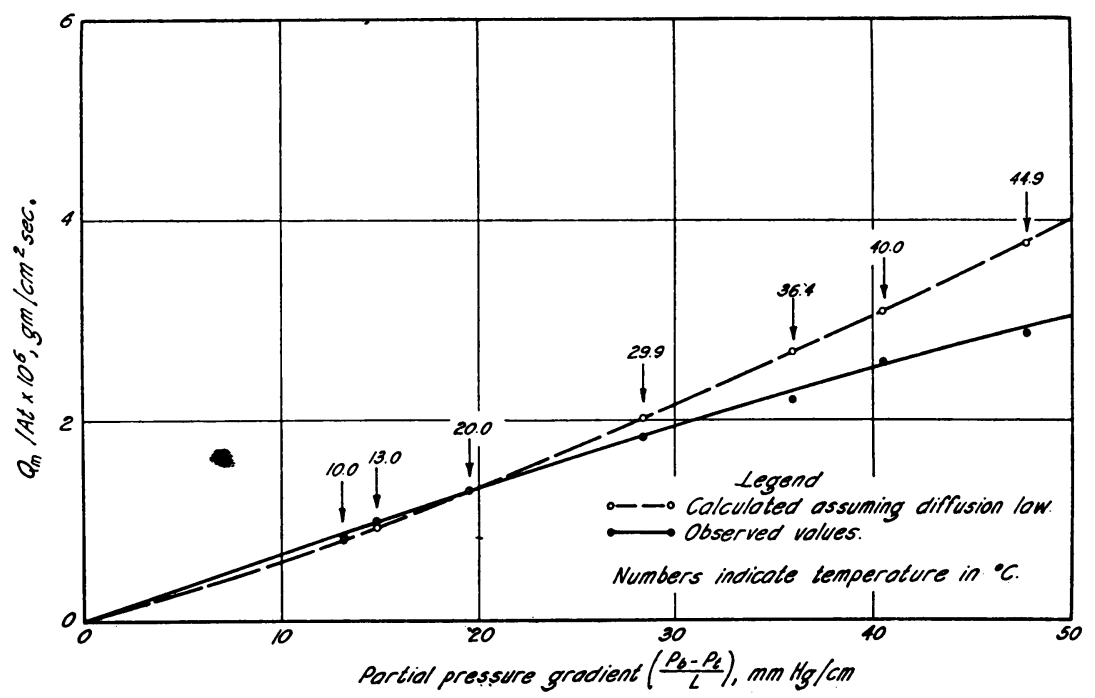

Fig. 6.-Departure of observed flow of $\mathrm{CS}_{2}$ vapor from flow values calculated by assuming diffusion law for run no. AGA (Yolo clay). 
Thus we observe experimentally that the law of diffusion is apparently not obeyed for the movement of $\mathrm{CS}_{2}$ vapor through columns of laboratory-packed soils under a partial-pressure gradient. Buckingham and Smith and Brown were not in a position to discover a failure of the diffusion law because they worked at a fixed temperature.

Turning to the conditions for which the theory of diffusion was derived, we perceive a reason for the failure of the diffusion law to predict the observed flows of gas through the soil. In deriving the diffusion law, equation 1 , which leads to equation 5 , one considers only impacts between molecules. One ignores the possible effect of impacts between molecules and the confining walls. For discussion of the derivation of the law of diffusion, the reader is referred to any complete text on kinetic theory (for example, Loeb, 1934, or Kennard, 1938). In the usual experiments involving diffusion, impacts on the walls may be neglected, for the dimensions of the passageway through which the diffusional flow is occurring are large as compared with the mean free path of the gaseous molecules. In soils, however, it is extremely doubtful that the impacts with the walls of the pores can be neglected.

The law of diffusion is the only physical law of flow developed for flow at constant pressure under a partial-pressure gradient. Yet from considering the conditions imposed in its derivation, one could not expect this law to be followed for gaseous movement in soils under a partialpressure gradient. Further, on the assumption of the previously stated relations between temperature and partial-pressure gradient, the failure of the law has been demonstrated experimentally. Inasmuch as the possible use of one of the laws of flow developed for total-pressure gradients, such as Poiseuille's, Darcy's (1856), or Knudsen's (1909) laws, for expression of flow under a partial-pressure gradient, involves considerations outside the scope of this present paper, the observed data have been fitted by an empirical equation.

Development of the Empirical Equation.-Assuming that flow is proportional to the partial-pressure gradient, one may write

$$
\frac{Q_{m}}{A t}=K \frac{\left(P_{b}-P_{t}\right)}{L}
$$

in which $K$ is an empirical constant. This is an assumption commonly made in flow studies. Its validity for the present case must now be examined.

In the first series of experiments (cf. table 2), the relation of flow to the gradient was investigated by varying the length of the soil column $L$ while holding the partial-pressure difference $\left(P_{b}-P_{t}\right)$ and the temperature $T$ constant. Under these conditions, if flow is proportional to the gradient, 
then the product $\left(Q_{m} / A t\right)(L)$ for any given soil condition must equal a constant, that is, $K\left(P_{b}-P_{t}\right)$. The data of table 2 show this to be the case. Further, if the assumption is correct, $\frac{\left(Q_{m} / A t\right)}{\left(P_{b}-P_{t}\right)}$ should, when $L$ is fixed, equal a constant; or $Q_{m} / A t$ when plotted against $\left(P_{b}-P_{t}\right)$ or $\frac{\left(P_{b}-P_{t}\right)}{L}$ should give a straight line, that is, a curve of slope $K$.

Referring to figures 5 and 6 , where $Q_{m} / A t$ as ordinates have been plotted against $\frac{\left(P_{b}-P_{t}\right)}{L}$ as abscissas, we see that a linear relation does not hold, but rather the observed points fall along a downward-bending curve. Evidently some factor is operating to decrease the observed flow below that to be expected from a direct proportionality between the flow $Q_{m} / A t$ and the gradient $\frac{\left(P_{b}-P_{t}\right)}{L}$. Remembering that under the experimental conditions the temperature increases with increasing values of $\frac{\left(P_{b}-P_{t}\right)}{L}$, it appears that the constant of equation 7 must contain a $L$
factor which causes its magnitude to diminish with increasing $\frac{\left(P_{b}-P_{t}\right)}{L}$ and temperature T. Equation 7 must be extended.

The viscosity of the $\mathrm{CS}_{2}$ vapor, which increases with temperature, has not been taken into account. If increased viscosity causes the decrease in the magnitude of the constant of equation 7 , then the viscosity $\eta$ must be introduced to modify equation 7 as follows:

$$
\frac{Q_{m}}{A t}=K \frac{1}{\eta} \frac{\left(P_{b}-P_{t}\right)}{L}
$$

This parallels the introduction by Emanueli (1927) and by Wyckoff and co-workers (1933) of a viscosity factor into the equation expressing Darcy's law to give in that equation a constant characteristic only of the porous medium and independent of the temperature and the fluid used.

Now, if the empirically developed equation 8 is to be obeyed by gases moving through soil under a partial-pressure gradient, and if the constant $K$ of the equation is to be truly constant for a given soil, then values of $Q_{m} / A t$ as ordinates plotted against $\frac{1}{\eta} \frac{\left(P_{b}-P_{t}\right)}{L}$ as abscissas should yield a straight line of constant slope equal to $K$ and passing through the origin. Such a plot has been made in figure 7, and the experimental points fitted to a linear function by the method of least squares. 
The relation between the viscosity of gases and temperature may be expressed according to Sutherland (1893) as follows:

$$
\eta=\eta_{o} \sqrt{\frac{T}{T_{o}}}\left(\frac{1+\frac{C_{s}}{T_{o}}}{1+\frac{C_{s}}{T}}\right)
$$

where $\eta$ and $\eta_{o}$ refer to the viscosities at the absolute temperatures $T$ and $T_{\circ}$ and where $C_{s}$ is a constant characteristic of the particular gas. A value of $C_{8}=496$ calculated by Titani (1933) according to a formula proposed by Arnold (1933) has been used in equation 9 to obtain the values of $\eta$ appearing in column 9 of table 3 . This value of $C_{s}$ agrees closely with Titani's experimental values and with those calculated by Rankine's (1910) formula. The value $\eta=96.4 \times 10^{-6}$ poise at $14.2^{\circ} \mathrm{C}$, taken from Suhrmann (1923), has been used as a base value in Sutherland's formula for converting to the temperatures of the experiments.

The empirically developed equation 8 will be recognized as a special form of the more general algebraic equation of the first degree, $y=$ $a+\beta x$; or, using the previous symbols,

$$
\frac{Q_{m}}{A t}=a+\frac{K^{\prime}}{\eta} \frac{\left(P_{b}-P_{t}\right)}{L}
$$

in which the intercept $a$ has been taken equal to zero. The intercept $a$ has been taken as zero in writing equation 8 , for we have assumed that when $\frac{\left(P_{b}-P_{t}\right)}{L}=0, Q_{m} / A t$ would be zero; that is, when the gradient was zero, there would be no net flow of $\mathrm{CS}_{2}$. One would expect this to be the case, but in order to justify setting $a=0$, one must fit the data by least squares to the general form of the first-degree equation-that is, equation 10and obtain the least squares values of the constants $a$ and $K^{\prime}$. To determine whether the calculated values of the intercept a depart significantly from zero, one may proceed as follows: ${ }^{9}$

Using the least squares values of the constants $a$ and $K^{\prime}$, calculate a value of $Q_{m} / A t$ for each observed value of $\frac{\left(P_{b}-P_{t}\right)}{L}$. From the residuals, $Q_{m} / A t-\left(Q_{m} / A t\right)_{c}$ (where the subscript $c$ refers to the calculated value), calculate the estimated probable error of a single observation $r_{s}{ }^{\prime}$ by

$$
r_{s}{ }^{\prime}=0.6745 \sqrt{\frac{\Sigma v^{2}}{(n-2)}}
$$

${ }^{9}$ This procedure has been developed in collaboration with Mr. P. R. Day. 
where $v$ is the residual $Q_{m} / A t-\left(Q_{m} / A t\right)_{c}$ and $n$ the number of observed points. The primes on $r_{s}^{\prime}$ and $K^{\prime}$ are introduced to distinguish these values from corresponding unprimed values calculated when $a$ was taken as zero. Now, from this value of the probable error of the intercept $a$, given by the symbol $r_{a}{ }^{\prime}$, using the following relation as given by Birge (1932),

$$
r_{a}^{\prime}=r_{s}^{\prime}\left(\frac{\Sigma x^{2}}{n \Sigma x^{2}-\left(\Sigma x^{2}\right)}\right)^{1 / 2}
$$

where quantities within the parentheses refer to the least-squares working table, in which $x$ represents the observed values of $\frac{1}{\eta} \frac{\left(P_{b}-P_{t}\right)}{L}$ for the $n$ observations.

One must bear in mind that the results of statistical analysis apply in a negative manner. As we have seen, there is some reason to believe that the intercept $a$ should be zero. The question now is, do the calculated values of $a$ and the estimated probable error of the intercept, $r_{a}^{\prime}$, support this contention? The "u-test" (normal probability integral) of Deming and Birge (1934) may be applied to express the chance that a given calculated value of $a$ departs significantly from zero. If the chances that the calculated value of $a$ does depart significantly from zero are found to be high, then the theoretical contention $a=0$ becomes doubtful. On the other hand, unless the chances are high for a significant departure, one can say the theoretical contention $a=0$ is not contrary to experiment.

Applying this analysis to the data of table 3 and figure 7, the values given in the following tabulation are found for the intercept $a$; the constant $K^{\prime}$; the estimated probable errors of a single observation $r_{s}^{\prime}$ and of the intercept $r_{a}{ }^{\prime}$; and the probability $P$ that the calculated value of $a$ departs significantly from zero:

a

$$
K^{\prime}
$$$$
r_{s}^{\prime}
$$$$
r_{\alpha}{ }^{\prime}
$$

Run no. AFZ $-0.0275 \times 10^{-6} 8.28 \times 10^{-12} \pm 0.0938 \times 10^{-6} \pm 0.0905 \times 10^{-6} 0.15$ Run no. AGA - $0.0356 \times 10^{-6} 6.66 \times 10^{-12} \pm 0.0309 \times 10^{-6} \pm 0.0298 \times 10^{-6} 0.55$

On theoretical grounds there is good reason to take $a=0$; and the statistical analysis has shown that this is not contrary to the experimental facts. In the more doubtful case, AGA, the probability is very close to that to be expected from pure chance. We can therefore set $a=0$ and accept the form of the empirical equation of flow 8.

Now, using the form of equation 8 , that is, setting $a=0$, the best leastsquares values of $K$ were obtained, together with their estimated probable errors $r_{K}$ calculated according to Birge (1932), using

$$
r_{K}=r_{s}\left(\frac{n}{n\left(\Sigma x^{2}\right)-(\Sigma x)^{2}}\right)^{1 / 2}
$$


Here $r_{s}$ is the estimated probable error of a single observation having set $a=0$, and the quantities within the parentheses have the same significance as in equation 12. The following tabulation gives the values of $K$, which we shall hereafter call the permeability ${ }^{10}$ and express as gram-

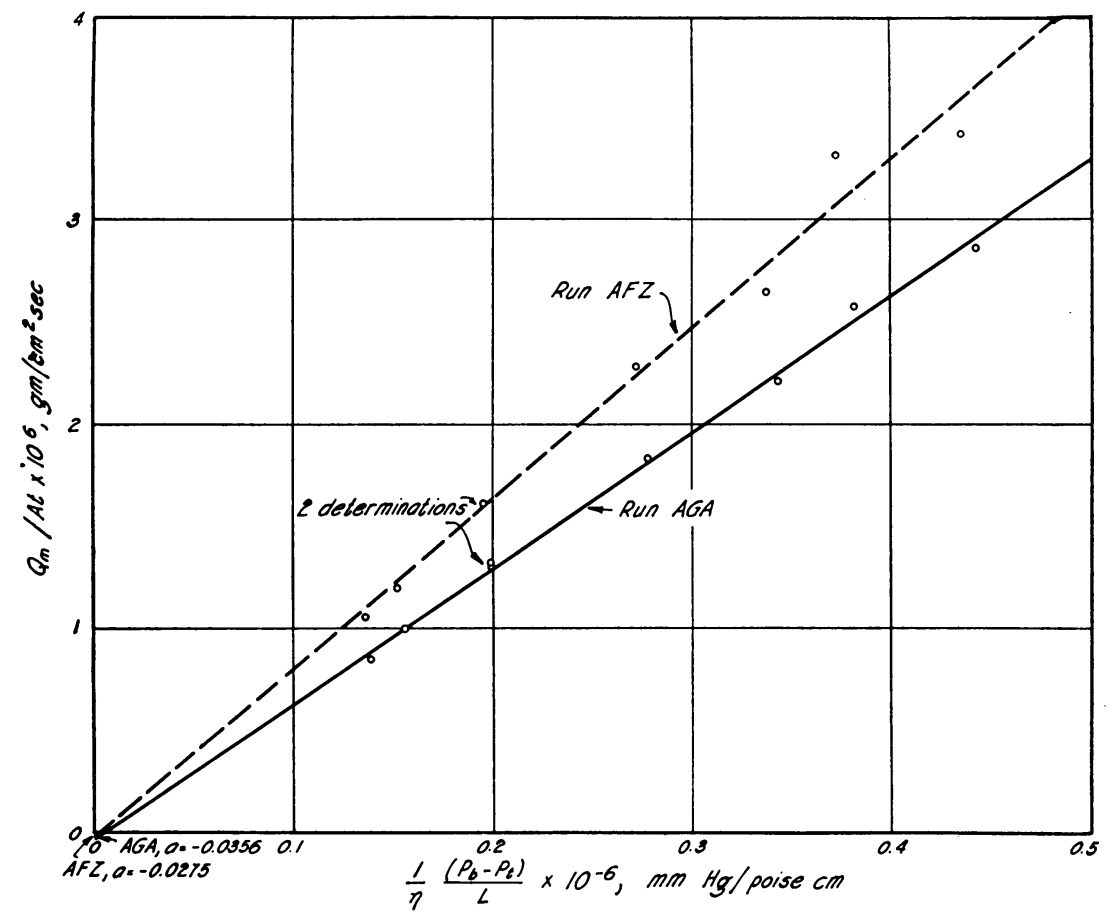

Fig. 7.-Observed flow of $\mathrm{CS}_{2}$ vapor plotted (by least-squares line) according to the empirical equation: $\frac{Q_{m}}{A t}=\frac{K}{\eta}\left(\frac{P_{b}-P}{L}\right)$.

poises $/ \mathrm{sec} . / \mathrm{cm}^{2}$ per unit partial-pressure gradient-that is, per millimeter of mercury difference in partial pressure $/ \mathrm{cm}$.

Soil

$K$

Run no. AFZ fine sandy loam Run no. AGA ................... clay

Relation of the Empirical Equation to Other Physical Laws.-Mention should be made of the relation of the measured flow of $\mathrm{CS}_{2}$ vapor through

${ }^{10}$ Some workers have assigned the word permeability specifically to the constant of Darcy's law. In a more general sense, permeability is an expression of the ability of fluids to pass through a porous material. The constant of Darcy's law calculated for a particular porous material is one means of evaluating this ability. In this paper the writer evaluates this property by using the constant $K$ of equation 8 . For brevity this constant $K$ will be referred to as the soil permeability. 
the soil, and the empirical expression developed for it, to the laws of flow derived from kinetic-theory considerations for flow under total-pressure gradients. Poiseuille's law takes into account impacts between molecules and impacts between molecules and the wall. It is derived by equating the momentum caused by the pressure drop in flowing through a tube to the momentum lost by viscous drag on the walls. If one assumes that such laws can be applied to flow under partial-pressure gradients, one might expect the $\mathrm{CS}_{2}$ flow observed in these experiments to be governed by Poiseuille's law, or by Darcy's law with the added viscosity term that can be shown to reduce to the same form as Poiseuille's law. For the flow of gases, Poiseuille's or Darcy's law may be written:

$$
\frac{Q_{m}}{A t}=\frac{K^{\prime \prime}}{\eta} \frac{M}{R_{0} T} \frac{\left(P_{1}^{2}-P_{2}^{2}\right)}{L}
$$

in which $K^{\prime \prime}$ is a constant, $M$ the molecular weight of the gas flowing, $R_{o}$ the universal gas constant, $T$ the absolute temperature, and $P_{1}$ and $P_{2}$ the total pressures at the ends of the tube. The derivation of Poiseuille's law implies conditions such that viscous transfer of momentum from the moving molecules to the walls can occur. This requires that the mean free path of the molecules $\lambda$, which for $\mathrm{CS}_{2}$ molecules at atmospheric pressure is of the order of magnitude of $0.5 \times 10^{-5} \mathrm{~cm}$., or 0.05 micron, be small as compared with the radius $R$ of the tube through which the gas flows.

The requirement that $\lambda$ be small as compared with $R$ in order that Poiseuille's law be followed casts doubt upon the applicability of this law to soils where some of the pores, at least, may be of the order of 0.05 micron. Knudsen (1909) has derived a law for flow under conditions such that $\lambda$ is of the same order as $R$. In his derivation (see Loeb, 1934), he considers impacts between molecules and wall to be more important than impacts between molecules, and arrives at the following law:

$$
\frac{Q_{m}}{A t}=\frac{K^{\prime \prime \prime}}{\sqrt{T}} \frac{\left(P_{1}-P_{2}\right)}{L}
$$

Here $K^{\prime \prime \prime}$ is another constant, and $T$ is the absolute temperature. Since 0.05 micron would seem small for pores in a granular soil, one might expect the measured flow of $\mathrm{CS}_{2}$ to fall between the flows as predicted by Poiseuille's and Knudsen's laws, provided we consider the interchangeability of the partial-pressure difference $\left(P_{b}-P_{t}\right)$ and the total pressure difference $\left(P_{1}-P_{2}\right)$.

It is interesting now to compare the empirically established flow equation 8 ,

$$
\frac{Q_{m}}{A t}=\frac{K}{\eta} \frac{\left(P_{b}-P_{t}\right)}{L}
$$


with equation 15 expressing Knudsen's law. Evidently the empirical equation is closely related to Knudsen's law, since $\eta$ varies approximately as $\sqrt{T}$. (See equation 9.)

For purposes of this project, however, we shall use the empirical expression 8, which is convenient and which well fits the experimental data. The ability of a soil to transmit $\mathrm{CS}_{2}$ under given conditions will be specified by the evaluation of the constant $K$ in the empirical flow equation, which we have referred to as the soil permeability. Wyckoff and coworkers (1939) have proposed a standard unit for permeability, the "darcy." Since this unit, as defined, involves flow expressed on a volume basis, it will not be used. Soil permeabilities will be expressed as grampoises per second per square centimeter per millimeter mercury difference in partial pressure of $\mathrm{CS}_{2}$ per centimeter length.

\section{DISCUSSION}

Under the laboratory conditions of this experiment, the soil porosity, when expressed according to Buckingham (1904), appears to be the controlling factor on the permeability of the soil to $\mathrm{CS}_{2}$ vapor. The degree of compaction (the apparent density value) and the soil moisture content apparently influence permeability to an extent dependent on their effect on porosity.

Buckingham defines porosity as the volume of gas in a given over-all volume of soil divided by that total volume; that is, it is an expression for the percentage of gas by volume:

$$
S=\left(\frac{V_{g}}{V_{g}+V_{w}+V_{s}}\right) 100
$$

Here $V_{g}, V_{w}$, and $V_{s}$ represent the volumes of the gas, water, and solid phases respectively. This definition of porosity should not be confused with the frequently used concept wherein porosity is given as the ratio of the nonsolids volume to the total volume. This latter porosity expresses the volume occupied by the gas and water phases, whereas Buckingham's expression considers the volume occupied by the gaseous phase only. Throughout this discussion porosity is used as defined by Buckingham. This manner of expressing porosity has also been followed by Green and Ampt (1911, 1912) and by Smith and Brown (1933).

Figure 8 presents graphically the experimental relation between the soil permeability for $\mathrm{CS}_{2}$ vapor and the soil porosity for Yolo fine sand. Whereas the points at the high-porosity end were obtained by compacting air-dry soil, the points at the low-porosity end were derived from studies on soils at different moisture contents. On extrapolation, note that the permeability approaches zero, not at zero porosity, but at a 
porosity near 26 per cent. According to experiments with other texturesfine sand, sandy loam, loam, and clay-permeability is also governed by porosity, but the relationship is not linear (fig. 9). Again, it should be noted that the permeability on extrapolation approaches zero at 26-29 per cent

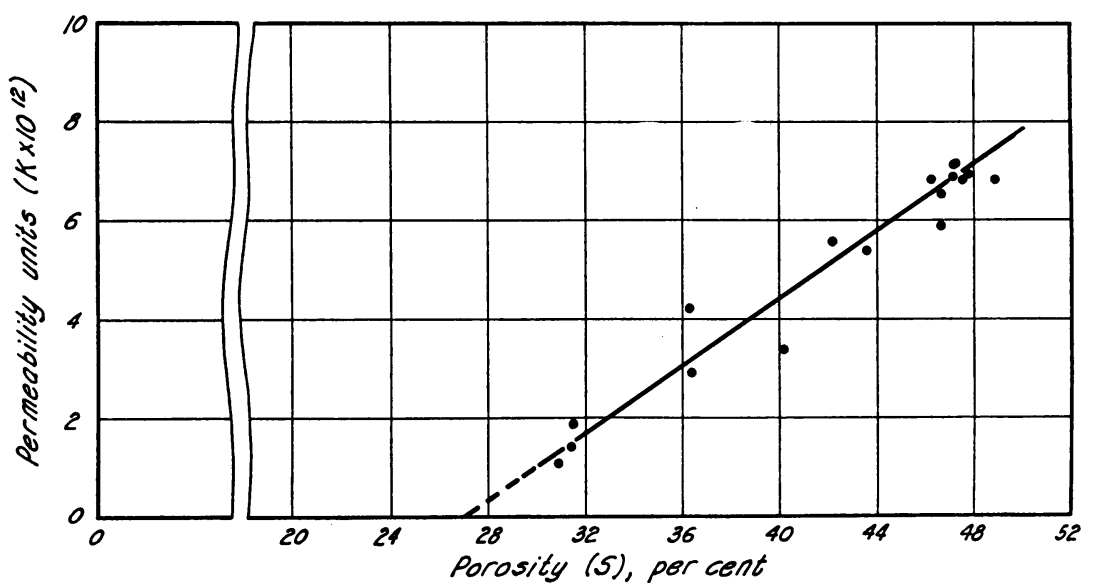

Fig. 8.-Relation of soil porosity to the permeability of the soil for $\mathrm{CS}_{2}$ vapor in Yolo fine sand.
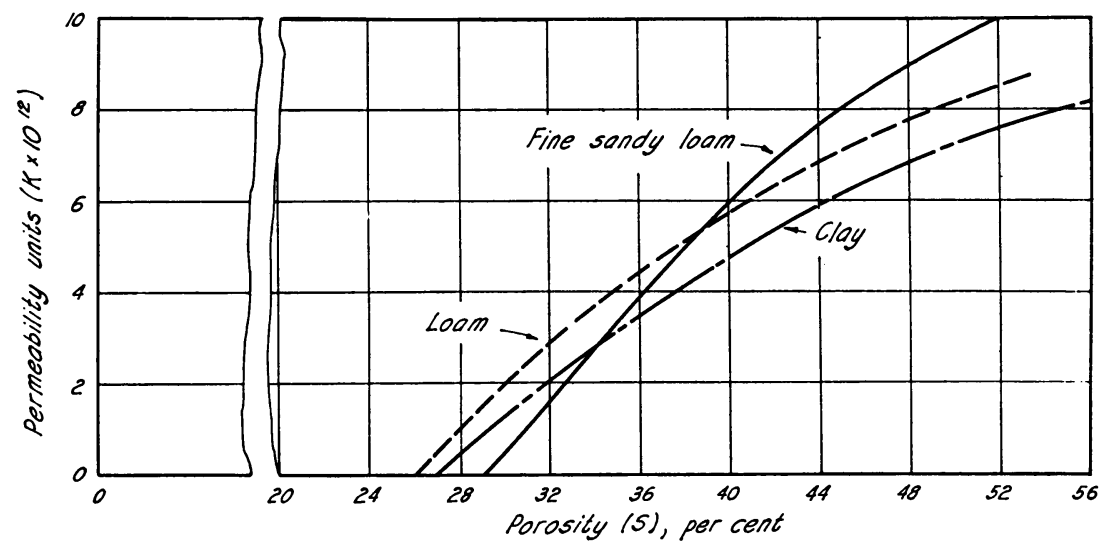

Fig. 9.-Relation of soil porosity to the permeability of the soil for $\mathrm{CS}_{2}$ vapor in Yolo fine sandy loam, Yolo loam, and Yolo clay.

porosity. This finding agrees with Green and Ampt, whose data for soils and for systems of glass beads, when extrapolated, indicate that the permeability would approach zero as the porosity decreased to the value near 30 per cent. Smith and Brown, experimenting with air-dry soils having a porosity range of 35 to 65 per cent, concluded that the flow of $\mathrm{CO}_{2}$ was a linear function of porosity. The rather bad scatter of their data 
over this range of porosity does not, however, allow an extrapolation to determine whether flow would approach zero at a finite porosity.

The literature contains several references to studies on the relation between porosity and permeability. The results reported are not in agreement, for Fancher, Lewis, and Barnes (1933) state there is no consistent relation between porosity and permeability; Muskat and his colleagues (Muskat and Botset, 1931, Wykoff, et al., 1933) declare that porosity cannot alone indicate the permeability accurately, but that porosity may be the primary property in determining permeability, and Buckingham, Green and Ampt, Howe and Hudson (1927), and Smith and Brown agree that permeability varies in the same direction as porosity, but disagree as to the extent to which the two are related.

Different soils vary in the ratio of continuous to discontinuous air spaces. This would seem to be a contributory factor in causing the soil textures to show unequal permeabilities to $\mathrm{CS}_{2}$ at a given total porosity. Texture is a term indicating the size distribution of particles in a soil. Differences in the properties of soils of unlike texture are caused not only by texture, but also by another factor-namely, structure. Structure expresses the arrangement of the individual grains and aggregates that make up the soil mass. It must, then, affect the shape and distribution of the voids in the soil, and hence the proportions of continuous to noncontinuous pores. Although laboratory samples of soils of various textures still possess structural differences, these differences have been reduced. The comparatively small differences in permeability shown by the unlike-textured soils in figure 8 would be expected to be greater under the natural structure conditions in the field.

Compaction.-Soils are frequently characterized by a statement of the degree of compaction, which is often expressed in terms of the "apparent density" $\rho_{a}$ of the soil calculated from the following relation:

$$
\rho_{a}=\frac{\text { mass of oven-dry soil }}{\text { apparent or total volume of this soil }}
$$

In a gross way the compaction of a soil expresses the closeness with which the soil particles have been squeezed together. The more compact a given soil, the smaller the pores or passageways between the individual particles. Since the degree of compaction is one factor controlling the free porosity of the soil, we should, from the previous discussion, expect the soil permeability to be a function of the apparent density value. Figures 10 and 11 give typical illustrations of this relation, using Yolo fine sandy loam and Yolo loam in the air-dry state.

Compaction studies were first to be undertaken. The rather bad scatter 
of values could probably be reduced if the work were to be repeated now that the apparatus and technique have been perfected.

Judging from these studies on laboratory-packed granular soils, the

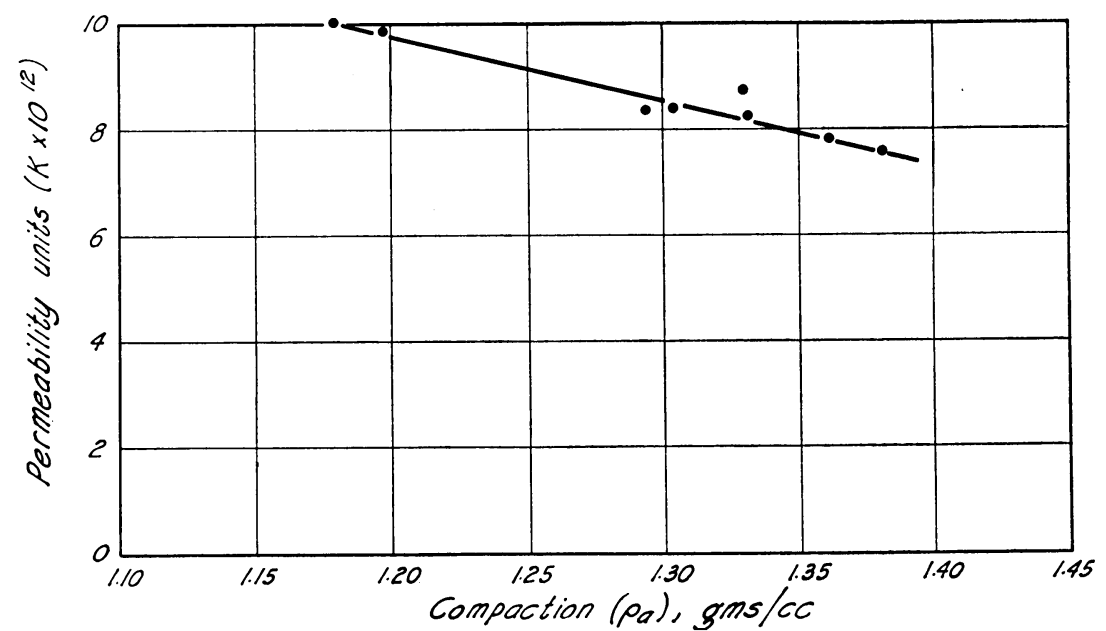

Fig. 10.- Influence of soil compaction (apparent density) on the permeability of the soil for $\mathrm{CS}_{2}$ vapor in Yolo fine sandy loam, at a soil moisture content of 3.00 per cent.

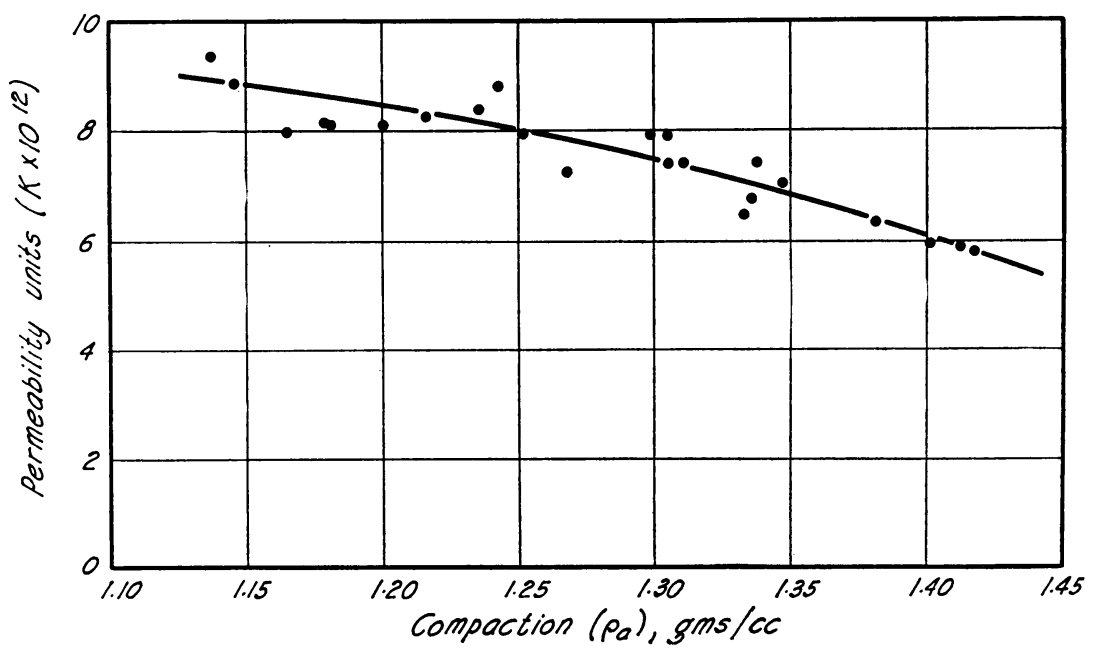

Fig. 11.-Influence of soil compaction (apparent density) on the permeability of the soil for $\mathrm{CS}_{2}$ vapor in Yolo loam, at a soil moisture content of 3.70 per cent.

influence of compaction on the permeability depends on the change in porosity produced. This statement agrees with the views of Smith and Brown. It is to be expected that the relation between compaction and 
permeability will be modified by structure. These studies have all been made on soils possessing necessarily artificial structures.

Field measurements show compaction to vary between rather wide limits, even for a given texture. For the Yolo Series of soils, field determinations on different textures gave a mean density value of $1.32 .{ }^{11}$ Though the range of compactions obtainable in these laboratory studies did not include all values experienced in the field, such curves as figures

TABLE 5

Effect of Moisture on the Permeability of Solls to CS Vapor* $^{*}$

\begin{tabular}{|c|c|c|c|c|}
\hline Soil type and run no. & $\begin{array}{c}\text { Moisture } \\
\text { equivalent }\end{array}$ & Field capacity & $\begin{array}{c}\text { Soil moisture } \\
\text { content at time } \\
\text { of run }\end{array}$ & $\begin{array}{l}\text { Permeability } \\
\text { (calculated to a } \\
\text { constant } \rho_{a} \text { ) }\end{array}$ \\
\hline & per cent & per cent & per cent & $K \times 10^{12}$ \\
\hline Fine sand: & & & & \\
\hline 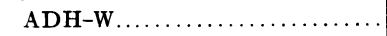 & 6.82 & 11.6 & 2.56 & 6.67 \\
\hline AFP $\ldots \ldots \ldots \ldots \ldots \ldots \ldots \ldots \ldots \ldots \ldots \ldots$ & 6.82 & 11.6 & 12.0 & 2.33 \\
\hline 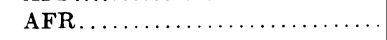 & 6.82 & 11.6 & 17.0 & 0.42 \\
\hline \multicolumn{5}{|l|}{ Fine sandy loam: } \\
\hline AFZ $\ldots \ldots \ldots$ & 17.26 & 18.0 & 2.85 & 9.61 \\
\hline AEY & 17.26 & 18.0 & 18.1 & 0.50 \\
\hline AEW ... & 17.26 & 18.0 & 18.8 & 0.12 \\
\hline \multicolumn{5}{|l|}{ Loam: } \\
\hline ACW-DR. & 22.99 & 22.4 & 3.82 & 8.86 \\
\hline AFG...... & 22.99 & 22.4 & 22.4 & 0.82 \\
\hline AFF $\ldots \ldots \ldots \ldots \ldots \ldots \ldots \ldots \ldots$ & 22.99 & 22.4 & 23.5 & 0.60 \\
\hline \multicolumn{5}{|l|}{ Clay: } \\
\hline ACD-I $\ldots \ldots \ldots \ldots \ldots \ldots \ldots$ & 30.44 & 31.3 & 6.10 & 8.10 \\
\hline AFH, AFS $\ldots \ldots \ldots \ldots \ldots \ldots \ldots$ & 30.44 & 31.3 & 31.4 & 0.26 \\
\hline 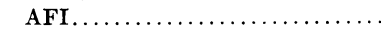 & 30.44 & 31.3 & 32.3 & 0.06 \\
\hline
\end{tabular}

* Degree of compaction constant for each texture.

9 and 10 do indicate the order of magnitude of differences in permeability that might be expected within the range commonly found in the field soils.

Field plots established on the University Farm at Davis to study the movement of $\mathrm{CS}_{2}$ vapor through the soil indicated that plowsoles could seriously hamper the distribution of the vapor in the soil. ${ }^{12}$ Unfortunately we do not have any measurements of the apparent densities on these particular plowsoles or on the undisturbed portion of the profiles of these soils, but Shaw and Bodman ${ }^{13}$ have made such determinations on a Ramona sandy loam. They found that the plowsole had apparent density values as high as 1.95, whereas the undisturbed soil had a value of 1.20.

${ }^{11}$ From the records of the Division of Irrigation Investigations and Practice.

${ }^{12}$ Unpublished data by A. S. Crafts and R. N. Raynor.

${ }^{13}$ Shaw, C. F., and G. B. Bodman. The plowsole. Division of Soils leaflet. 1928. (Mimeo.) 
The range of compaction covered in the curves of figures 10 and 11 must be greatly extended to include such a value as 1.95 . To give an approximation to the effect of plowsoles on permeability to $\mathrm{CS}_{2}$ vapor, the curve for fine sandy loam (fig. 10) has been extrapolated to an apparent density value of 1.95 . This gives a permeability of 0.5 to 1.0 unit. (See page 108 for definition of unit.) By comparing this low value of permeability with those given in figure 10, one may see more adequately the possible effect of compaction on permeability.

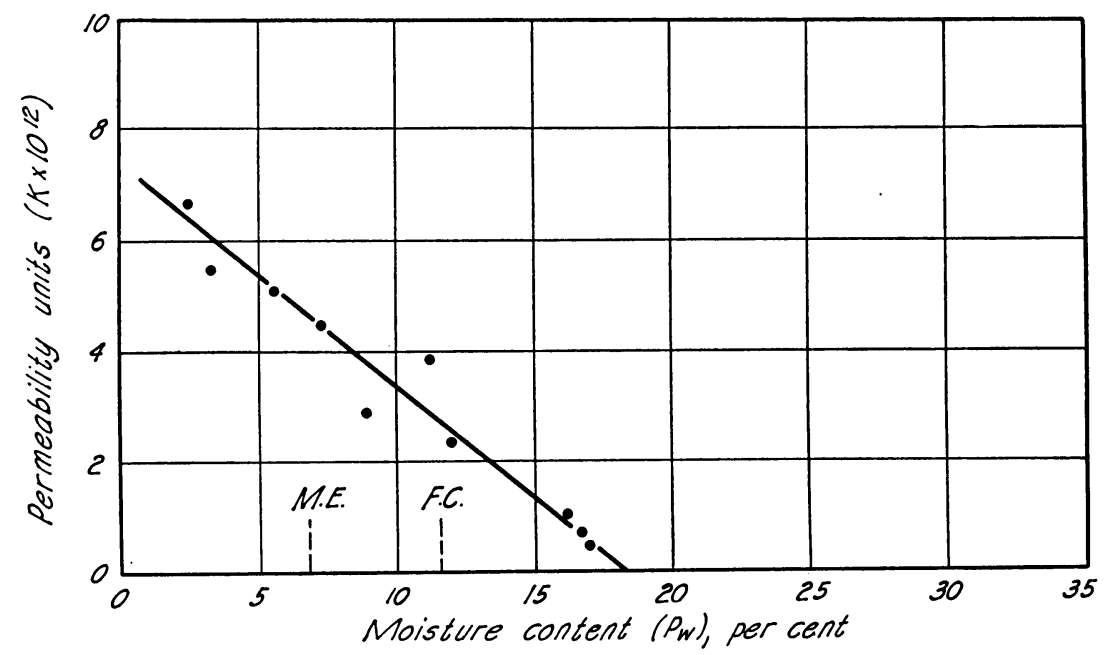

Fig. 12.- Influence of soil moisture content on the permeability of the soil for $\mathrm{CS}_{2}$ vapor in Yolo fine sand, calculated to an apparent density of 1.325 grams per cubic centimeter.

Moisture Content.- - The moisture content of the soil affects its permeability to $\mathrm{CS}_{2}$ vapor more than does any other variable studied. The addition of water to soil can greatly reduce the free porosity. Table 5 gives the permeabilities of four soils for the air-dry state and for moisture contents near their field capacities. Figures 12 and 13 plot permeability against the soil moisture content for two soils-Yolo fine sand and Yolo fine sandy loam. Although points at the air-dry and field-capacity ends of the curves are relatively easy to obtain, the intermediate moisture contents present many difficulties. To wet a soil uniformly to a moisture content below the field capacity special techniques are required. Fairly satisfactory methods have been devised to obtain the desired moisture contents, but it has been necessary to store the moistened soils for many months to achieve uniform moisture distribution.

Since a certain variation in the apparent density value of successive 
columns of packed soil is inevitable, a correction to constant apparent density for each texture has been made in the values of permeability $K$ recorded in table 5 . This is necessary in order to have the moisture content the only operative variable. The corrected $K$ has been calculated from the observed $K$ by assuming that the variation of $K$ with change in apparent density is proportional to the change in free porosity produced by the change in apparent density.

Perhaps the most striking and significant observation made in these studies is the great reduction in permeability with increasing moisture content. With the sand, permeability approaches a very low value at

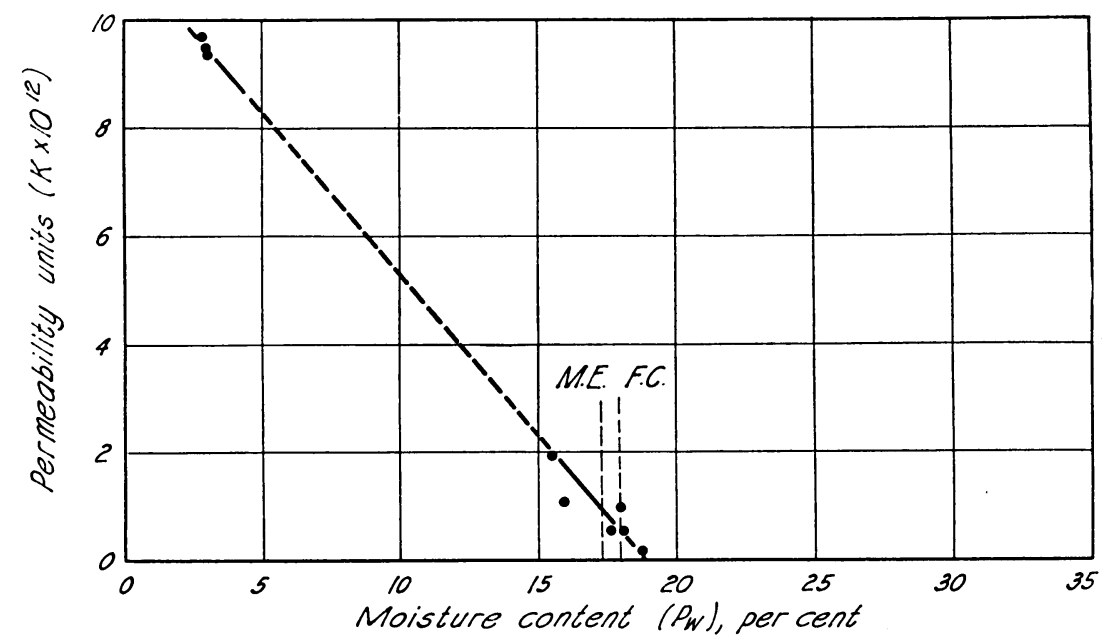

Fig. 13.- Influence of soil moisture content on the permeability of the soil for $\mathrm{CS}_{2}$ vapor in Yolo fine sandy loam, calculated to an apparent density of 1.258 grams per cubic centimeter.

moisture contents near the field capacity, a fact possibly explainable on the basis of the large average grain size with correspondingly large channels between the particles. Further addition of moisture to the sand, however, does reduce the permeability to a low figure. This observation of very low permeability to $\mathrm{CS}_{2}$ vapor in soils at their field capacity should be important in interpreting soil-fumigation studies carried out under field conditions and in soil-aeration relations in general.

\section{SUMMARY}

This investigation was undertaken to establish quantitatively the relation that each of several soil factors bears to the movement of $\mathrm{CS}_{2}$ vapor through the soil. Success or failure in using $\mathrm{CS}_{2}$ for weed and fungus control depends on the ability of the $\mathrm{CS}_{2}$ to move in the soil and on the pre- 
vention of its escape from the soil surface during and immediately after treatments. Satisfactory field application must be based on a knowledge of the effect that each soil factor, including soil porosity, texture, degree of compaction, and moisture content, has on $\mathrm{CS}_{2}$ movement in and out of the soil.

The method of field application of $\mathrm{CS}_{2}$ for controlling deep-rooted perennials is briefly reviewed.

The comparatively limited literature on gaseous movement in soils is discussed. In normal soil the gaseous phase throughout is at a constant pressure, the movement of $\mathrm{CO}_{2}$ and $\mathrm{O}_{2}$, and other gases normally present, as well as the movements of fumigants that may be introduced, results from differences in concentration or partial pressures of the particular gas from point to point. This problem of flow of gases in soils at constant total pressure in response to a partial-pressure gradient is considered in relation to the more generally treated problem of gaseous flow in response to a total-pressure difference.

The soil whose gaseous permeability is to be measured is packed into tubes to a known compaction and a definite moisture content. A shallow dish is sealed to the lower end of the soil tube into which the liquid $\mathrm{CS}_{2}$ is measured, and an "air-sweeper" is attached to the upper end of the soil tube. The $\mathrm{CS}_{2}$ is vaporized in a shallow dish, and the vapors, moving upward through the soil and rising from its upper surface, are collected by the air-sweeper and carried into absorber columns, where the amount of $\mathrm{CS}_{2}$ passing through the soil may be chemically determined. The apparatus required is fully described.

The method used possesses several advantages besides having the flow take place at a constant total pressure. It provides a system permitting a continuous record of the flow of $\mathrm{CS}_{2}$ vapor. For general soil permeability and soil-texture studies, the use of a gas like $\mathrm{CS}_{2}$, which does not normally occur in soils and does not alter the soil structure, eliminates the complexities involved in using $\mathrm{CO}_{2}$, which is affected by biological activity.

Judging from the experimental values for the flow of $\mathrm{CS}_{2}$ vapor through tubes of artificially packed soil carried out at different temperatures, the law of diffusion implied by Buckingham (1904) is not followed. A reason for the failure of the classical diffusion law to apply for gases moving in soils is suggested from an analysis of the kinetic-theory conditions imposed in the derivation of the law.

An empirical equation of flow has been developed to express the measured flows of $\mathrm{CS}_{2}$ vapor. The relation of this empirically established equation to other physical laws of flow is discussed.

Under the conditions of the experiments, the free porosity is apparently the controlling factor on the permeability of the soil to $\mathrm{CS}_{2}$ vapor. The 
permeability of these artificially packed soil columns has been found to approach zero, not at zero free porosity, but in a porosity range of 26 to 29 per cent. These relations are graphically presented for several textures.

Permeability is found to vary with soil texture, but the differences are smaller than would be expected under natural structure conditions of the field. The degree of compaction of the soil is found to control permeability in the extent to which the free porosity is changed. As field-plot trials have shown, compact layers in soils, such as plowsoles, will interfere seriously with the distribution of $\mathbf{C S}_{2}$.

The moisture content of the soil affects the permeability of the soil to $\mathrm{CS}_{2}$ vapor more than does any other variable studied. Great reductions in permeability have been found with increasing moisture content. Permeability approaches a very low value at moisture contents near the field capacity for all textures except fine sand.

\section{ACKNOWLEDGMENTS}

The author is indebted to the Wheeler, Reynolds, and Stauffer Chemical Company for the generous grant that has made possible this work. To Dr. A. S. Crafts and Mr. R. N. Raynor of the Division of Botany at Davis, to Dr. G. B. Bodman, Dr. R. E. Moore, and Mr. P. R. Day of the Division of Soils, and to Dr. L. B. Loeb of the Department of Physics, it is a pleasure to express gratitude for many helpful suggestions and words of encouragement. Also sincere thanks are expressed to Mr. H. A. Hannesson for his painstaking assistance with much of the tedious laboratory work. 


\section{LITERATURE CITED}

ARnold, J. H.

1933. Vapor viscosities and the Sutherland equation. Jour. Chem. Physics 1:170-76.

BIRGE, R. T.

1932. Calculation of errors by the method of least squares. Physical Review 40:207-27.

Buckingham, E.

1904. Contribution to our knowledge of the aeration of soils. U.S. Dept. Agr. Bur. Soils Bul. 25:1-52.

BUEHRER, T. F.

1932. The movement of gases through the soil as a criterion of soil structure. Arizona Agr. Exp. Sta. Tech. Bul. 39:1-57.

DARCY, H.

1856. Exposition et application des principes à suivre et des formulas à employer dans les questions de distribution d'eau. "Les fontaines publiques de la villa de Dijon."

Deming, W. E., and R. T. Birge.

1934. On the statistical theory of errors. Reviews of Modern Physics 6:119-61.

EMANUELI, L.

1927. The Emanueli porosity tester. An instrument for measuring the porosity of paper. Paper Trade Jour. 85:48-50 (Sept. 7).

Fancher, G. H., J. A. Lewis, and K. B. Barnes.

1933. Some physical characteristics of oil sands. Min. Ind. Exp. Sta. Pennsylvania State College Bul. 12:65-167.

Fleming, W. E., and F. E. Baker.

1935. The use of carbon disulfide against the Japanese beetle. U. S. Dept. Agr. Tech. Bul. 478:1-91.

Furnas, C. C.

1929. Flow of gases through beds of broken solids. U. S. Bur. Mines Bul. 307: $1-144$.

Green, W. H., and G. A. Ampt.

1911. Studies on soil physics. I. The flow of air and water through soils. Jour. Agr. Sci. 4:1-24.

1912. Studies on soil physics. II. Permeability of an ideal soil to air and water. Jour. Agr. Sci. 5:1-26.

Higgins, J. C., and A. G. Pollard.

1937. Studies in soil fumigation. II. Distribution of $\mathrm{CS}_{2}$ in soils fumigated under various conditions. Ann. Appl. Biol. 24:895-910.

Howe, W. L., and C. J. Hudson.

1927. Studies in porosity and permeability characteristics of porous bodies. Amer. Ceramic Soc. Jour. 10:443-48. 
Kennard, E. H.

1938. Kinetic theory of gases. 1st ed. 483 p. McGraw-Hill Book Co., New York, N. Y.

KING, F. H.

1897-98. Principles and conditions of the movement of ground water. U. S. Geol. Survey Annual Report 19 (Part 2): 59-300.

KNUDSEN, M.

1909. Die Gesetze der Molekularströmung und der inneren Reibungsströmung der Gase durch Röhren. Ann. Physik 28:75-130.

LANDOLT-BORNSTEIN.

1923. Physikalisch-chemische Tabellen. 1:251. Julius Springer, Berlin.

LOEB, L. B.

1934. The kinetic theory of gases. 2nd ed. 687 p. McGraw-Hill Book Co., New York, N. Y.

Matuszak, M. P.

1932. Iodometric determination of carbon disulfide. Indus. and Engin. Chem., anal. ed. 4:98-9.

Moore, R. E.

1939. Water conduction from shallow water tables. Hilgardia 12:383-426.

Muskat, M., and H. G. Botset.

1931. Flow of gas through porous materials. Physics 1:27-47.

National Research Council.

1929. International critical tables of numerical data, physics, chemistry, and technology 5:62. McGraw-Hill Book Co., New York, N. Y.

RANKIne, A. O.

1910. On the variation with temperature of the viscosities of the gases of the Argon group. Roy. Soc. London Proc. Ser. A. 84:181-92.

SLICHTER, C. S.

1897-98. Theoretical investigation of the motion of ground waters. U. S. Geol. Survey Annual Report 19 (Part 2): 301-84.

Sмiтh, F. B., and P. E. Brown.

1933. The diffusion of carbon dioxide through soils. Soil Sci. 35:413-24.

SUHRManN, R.

1923. Über die Druckabhängigkeit der Dämpfung einer um ihre vertikale Achse schwingenden Scheibe. Zeit. für Physik 14:56-62.

Sutherland, W.

1893. The viscosity of gases and molecular force. Phil. Mag. 36:507-31.

Titani, $\mathrm{T}$.

1933. The viscosity of vapors of organic compounds. Chem. Soc. Japan Bul. 8:255-76.

Wyckoff, R. D., H. G. Botset, M. Muskat, and D. W. Reed.

1933. The measurement of the permeability of porous media for homogeneous fluids. Rev. Sci. Instruments 4:394-405. 